\title{
Transcription Factors involved in Abiotic stress responses in Maize (Zea mays L.) and their roles in Enhanced Productivity in the Post Genomics Era.
}

\author{
Roy Njoroge Kimotho ${ }^{1,2}$, Elamin Hafiz Baillo ${ }^{1,2}$, Zhengbin Zhang ${ }^{\text {Corresp. 1, 2, } 3}$ \\ ${ }^{1}$ Key Laboratory of Agricultural Water Resources, Hebei Laboratory of Agricultural Water saving, Center for Agricultural Resources Research, Institute of \\ Genetics and Developmental Biology, Chinese Academy of Sciences, Shijiazhuang, Hebei, China \\ 2 University of Chinese Academy of Sciences, Beijing, Beijing, China \\ ${ }^{3}$ The innovative Academy of Seed Design, Chinese Academy of Sciences, Beijing, Beijing, China \\ Corresponding Author: Zhengbin Zhang \\ Email address: zzb@sjziam.ac.cn
}

Background: Maize (Zea mays L.) is a principal cereal crop cultivated worldwide for human food, animal feed, and more recently as a source of biofuel. However, as a direct consequence of water insufficiency and climate change, frequent occurrences of both biotic and abiotic stresses have been reported in various regions around the world, and recently, this has become a constant threat in increasing global maize yields. Plants respond to abiotic stresses by utilizing the activities of transcription factors, which are families of genes coding for specific transcription factor proteins. Transcription factor target genes form a regulon that is involved in the repression/activation of genes associated with abiotic stress responses. Therefore, it is of uttermost importance to have a systematic study on each transcription factor family, the downstream target genes they regulate, and the specific transcription factor genes involved in multiple abiotic stress responses in maize and other staple crops.

Method: In this review, the main transcription factor families, the specific transcription factor genes and their regulons that are involved in abiotic stress regulation will be briefly discussed. Great emphasis will be given on maize abiotic stress improvement throughout this review, although other examples from different plants like rice, Arabidopsis, wheat, and barley will be used.

Results: We have described in detail the main transcription factor families in maize that take part in abiotic stress responses together with their regulons. Furthermore, we have also briefly described the utilization of high-efficiency technologies in the study and characterization of TFs involved in the abiotic stress regulatory networks in plants with an emphasis on increasing maize production. Examples of these technologies include next-generation sequencing, microarray analysis, machine learning and RNA-Seq.

Conclusion: In conclusion, it is expected that all the information provided in this review will in time contribute to the use of TF genes in the research, breeding, and development of new abiotic stress tolerant maize cultivars. 
1 Transcription Factors Involved in Abiotic Stress Responses in Maize 2 (Zea mays L.) and Their Roles in Enhanced Productivity in the Post 3 Genomics Era.

5 Roy Njoroge Kimotho ${ }^{1,2}$, Elamin Hafiz Baillo ${ }^{1,2}$ and Zhengbin Zhang ${ }^{* 1,2,3}$

${ }^{1}$ Key Laboratory of Agricultural Water Resources, Hebei Laboratory of Agricultural Water saving, Center for Agricultural Resources Research, Institute of Genetics and Developmental Biology, Chinese Academy of Sciences, 286 Huaizhong Road, Shijiazhuang 050021, China

${ }^{2}$ University of Chinese Academy of Sciences, Beijing, China, 100049

${ }^{3}$ The innovative Academy of Seed Design, Chinese Academy of Sciences, 100101

Number of words: 11974

Number of Tables: 2

Number of Figures: 2

\section{*Corresponding author}

Prof Zhengbin Zhang

Center for Agriculture Resources Research, Institute of Genetics and Developmental Biology

Chinese Academy of Sciences, China

Address: Shijiazhuang, Hebei, China

Tel: (0311) 85886648; Fax: (0311) 85815093

Mobile: +8613691578380

Email: zzb@sjziam.ac.cn 
31

32

33

34

35

36

37

38

39

40

7 9

\begin{abstract}
Background: Maize (Zea mays L.) is a principal cereal crop cultivated worldwide for human food, animal feed, and more recently as a source of biofuel. However, as a direct consequence of water insufficiency and climate change, frequent occurrences of both biotic and abiotic stresses have been reported in various regions around the world, and recently, this has become a constant threat in increasing global maize yields. Plants respond to abiotic stresses by utilizing the activities of transcription factors, which are families of genes coding for specific transcription factor proteins. Transcription factor target genes form a regulon that is involved in the repression/activation of genes associated with abiotic stress responses. Therefore, it is of uttermost importance to have a systematic study on each transcription factor family, the downstream target genes they regulate, and the specific transcription factor genes involved in multiple abiotic stress responses in maize and other staple crops.
\end{abstract}

Method: In this review, the main transcription factor families, the specific transcription factor genes and their regulons that are involved in abiotic stress regulation will be briefly discussed. Great emphasis will be given on maize abiotic stress improvement throughout this review, although other examples from different plants like rice, Arabidopsis, wheat, and barley will be used.

Results: We have described in detail the main transcription factor families in maize that take part in abiotic stress responses together with their regulons. Furthermore, we have also briefly described the utilization of high-efficiency technologies in the study and characterization of TFs involved in the abiotic stress regulatory networks in plants with an emphasis on increasing maize production. Examples of these technologies include next-generation sequencing, microarray analysis, machine learning and RNA-Seq.

Conclusion: In conclusion, it is expected that all the information provided in this review will in time contribute to the use of TF genes in the research, breeding, and development of new abiotic stress tolerant maize cultivars. 8

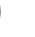




\section{Introduction}

Abiotic stresses for instance drought, salinity, cold, high temperatures and mineral toxicity are the main cause of major crop yield reductions worldwide, reducing expected average yields of the major crops by more than 50\% (Prasad et al., 2011; Mahalingam, 2015). Plants are sessile beings that are continuously exposed to various changes in the environmental conditions. Variations in the environment involving both biotic and abiotic stresses have negative effects on economically important crops like maize (Ramegowda and Senthil-Kumar, 2015). Evolutionary changes have helped many plants adapt to different adverse conditions. Some species show a marked increase in tolerance to various abiotic stresses compared to others (Phukan et al., 2014). Due to global warming and the climatic abnormalities accompanying it, the frequencies of combined biotic and abiotic stresses have significantly increased, leading to reduced growth and yield of the major crops worldwide (Mittler., 2006; Pandy et al., 2015; Ramegowda and SenthilKumar, 2015). Moreover, continuous manifestations of abiotic stresses such as heat and drought together, has led to severe reductions in crop yields as opposed to when these stresses occur separately during the different growth stages (Mittler., 2006; Prasad et al., 2011).

Maize (Zea mays ssp. Mays L) is one of the most important cereal crops cultivated worldwide (particularly in Africa and South America). Global maize production increased from 255 million tonnes in 1968 to 1,134 million tonnes in 2017 representing an average annual growth of 3.46\%.

(https://knoema.com/atlas/World/topics/Agriculture/Crops-Production-Quantity-tonnes/Maizeproduction). Maize production has significantly enlarged in both the developing countries and the developed countries (Wang et al., 2013).

Maize is a staple food in many parts of the world; it is consumed directly by humans, used for animal feed, and in other maize products such as corn syrup and corn starch. In the last century, maize has been utilized as a model system in the study of various biological events and systems including paramutation, transposition, allelic diversity, and heterosis (Bennetzen and Hake., 2009). Recently, maize has been identified as a potential sustainable feedstock, as well as a model system for research in the bioenergy and biofuel industries (Perlack et al., 2005). Continuous study in maize genetics has led to further understanding of other related C4 grasses such as Elephant grass (Miscanthus gigantus) and switchgrass (Panicum virgatum) as scientists aim to develop and domesticate these plants (Perlack et al., 2005). However, maize belts around the world which range from the latitude $40^{\circ}$ South to the latitude $58^{\circ}$ North are exposed to continuous effects of both biotic and abiotic stresses (Gong et al., 2014). Abiotic stresses, like salinity, drought, nutrient deficiency, and high and low temperatures are the major environmental factors that negatively influence maize production. In particular, intense waterlogging, extreme temperatures, and drought have significantly affected maize yields (Ahuja et al., 2010).

Plants must cope with a variety of abiotic stresses including extreme temperatures, heavy metals, osmotic stresses, and high light intensity. Under stress, accumulation of some metabolites positively regulates plants response to both abiotic and biotic stresses thus protecting plants from multiple stresses (Rasmussen et al., 2013). Changes in ions fluxes, callose accumulation, phytohormones, and ROS are the first responses induced to tackle the stresses, leading to metabolic reprogramming in the plants defenses (Bartoli et al., 2013).

Reactive oxygen species such as hydrogen peroxide $\left(\mathrm{H}_{2} \mathrm{O}_{2}\right)$ and superoxide $\left(\cdot \mathrm{O}-{ }_{2}\right)$ which are produced due to oxidative stresses, inhibit photosynthesis and cause vast cellular destruction 
110 (Allan and Fluhr, 2007). ROS are normally removed rapidly by antioxidative mechanisms, 111 although this removal can be hindered by the stresses leading to an increase in ROS 112 concentration inside the cells, and further increasing the damage caused (Allan and Fluhr, 2007).

113 Another pathway involved in abiotic stress responses in plants is the Mitogen-Activated Protein 114 Kinase (MAPK) cascades. MAPK cascades are activated following the recognition and 115 perception of stress stimuli and control the stress response pathways (Wurzinger et al., 2011). 116 They are highly conserved in eukaryotes and are responsible for signal transduction in various cellular processes under different biotic and abiotic stress responses. Because MAPKs are involved in various stress responses, they play a main role in the combination of biotic and abiotic stresses (Amajová et al., 2013).

Additionally, hormone signaling in plants is another important pathway involved in biotic and abiotic stress responses and the primary hormone involved is ABA. An increase in ABA concentration in plants under abiotic stress modulates the abiotic stress-regulation network (Xiong et al., 2002), while biotic stress is mediated by antagonism in other stress hormones such as JA/ET and SA (Liu et al., 2008). The role of ABA in abiotic stress responses has been widely described throughout this review.

Plants do not respond to multiple stresses by way of a linear pathway. The responses are complex circuits involving various pathways in tissues, cellular specific compartments and the interactions of signaling molecules in controlling a particular response to a stimulus (Dombrowski, 2003). Due to abiotic stresses, numerous proteins and gene transcripts are altered through the regulation of protein turnover and gene expression (Jiang et al., 2007; Wong et al., 2006).

In this review, we will briefly describe the main TF families and the interactions of these TFs with the cis-acting elements (CREs) which are present in the promoter regions of stress responsive genes. Even though TF regulons have been described recently by (Gahlaut et al 2016; Joshi et al., 2016), this review will focus on TFs involved in abiotic stress tolerance with a specific focus on maize. We will also focus on new ways of increasing production of maize by utilizing currently available genomic information, tools and data.

\section{Survey methodology}

All published manuscripts cited in this review were obtained from different databases including Pubmed, Web of Science, EBSCO, Google Scholar, research gate, Science Direct, SCOPUS, JSTOR, SciELO, and Semantic Scholar. Key words such as "maize stress tolerance", "transcription factors involved in abiotic stress responses", "abiotic stress", "transcription factor downstream genes", and "regulons involved in abiotic stress" were searched between 10 January to 25 October 2018. We have critically analyzed articles to provide an in-depth and comprehensive research trend focusing on the TFs involved in abiotic stress tolerance in maize. Furthermore, we have provided perspectives on the latest research as well as previous findings with focus on TF families involved in abiotic stress responses in maize. 


\section{Functions of Transcription Factors}

153

154

155

156

157

158

159

160

161

162

163

164

165

166

167

168

169

170

171

172

173

174

175

176

177

178

179

180

181

182

183

184

185

186

187

188

189

190

191

192

193

Abiotic stress-induced genes are generally classified into two main groups based on their protein products. One type includes the genes coding for products which directly allow cells to resist environmental stresses for instance osmotic regulatory protein, late embryogenesis abundant (LEA) protein, enzymes synthesizing proline, betamine, malondialdehyde (MDA) and other osmotic regulators and anti-freezing proteins (Loredana et al., 2011). The second type of genes are regulatory proteins which operate in the signal transduction networks, for example, molecular chaperones, functional proteins, and transcription factors (TFs) or kinases (Song et al., 2013; Loredana et al., 2011).

Networks of transcription factors together with transcription factor binding sites (TFBS) directly control transcriptional regulation of plant genes (Chaves and Oliveira, 2004). Transcription factors are proteins usually consisting of two domains, namely (1) the DNA binding domain (DB) and (2) an activation domain (AD). A TF binds to the cis-acting element (TF binding site) located in the promoter region of a stress-induced gene with the support of a DB domain (Yamasaki et al., 2013). This event brings the AD close to the target gene leading to repression or activation of this gene. A large percentage of genes in the plant genome (nearly 10\%) essentially encode for transcription factors (Franco-Zorrilla et al., 2014). TFs activate or repress the activity of RNA polymerase, leading to gene regulation. TFs can be categorized into various families based on their DNA binding domains (Riechmann et al., 2000). Since abiotic stresses are quantitative traits that might require regulation of several genes including the TF genes, and since a single transcription factor may regulate several genes that are involved in abiotic stress tolerance. A detailed study of all TFs associated with abiotic stress regulatory mechanisms in maize will be significantly rewarding. For example, Xu et al. (2006) successfully converted flood sensitive rice genotypes into flood-tolerant varieties by introgression of the subl locus which encodes an (ethylene response factor) TF, leading to the induction of about 900 stress-responsive genes.

TF DNA-binding domains are strongly conserved between species, to the extent of using these characteristics to classify the TFs into various families (Fig. 1). These families differ among plant species in that different plant systems have between 26 to 83 TFs families (Jin et al., 2014). In Arabidopsis, for instance, approximately 34 families consisting of 1533 TFs have so far been classified (Riechmann et al., 2000). Additionally, in Arabidopsis and many other plants, transcriptome data revealed a number of pathways which respond to abiotic stresses independently, pointing to the possibility that susceptibility or tolerance of both biotic and abiotic stresses are controlled by a sophisticated gene regulatory network at the transcriptome level (Umezawa et al., 2006).

Abscisic acid (ABA) is the principal hormone involved in the coordination of abiotic stress in plants (Fig. 1). This hormone regulates a complex gene regulatory system that enables plants to handle decreased moisture availability (Cutler et al., 2010). ABA-dependent gene activation pathways were identified as pathways which determine stress tolerance by the induction of at least two separate regulons: the first one is the myeloblastosis oncogene (MYB)/ myelocytomatosis oncogene (MYC) regulon and the second one, is the ABA-responsive element binding protein/ ABA-binding factor (AREB/ ABF) (Abe et al., 1997; Saibo et al., 2009) (Fig. 
194 1). ABA- independent regulons include; the NAC (CUC, NAM and ATAF) and the zinc-finger homeodomain (ZF-HD) regulon (Nakashima et al., 2009; Saibo et al., 2009) (Fig. 1).

196

197

198

199

200

201

202

203

204

205

206

207

208

209

210

211

212

213

214

215

216

217

218

219

220

221

222

223

224

225

226

227

228

229

230

231

232

233

234

235

236

237

The different stress tolerance responsive TFs normally function independently, although there is a possibility that some level of cross-link occurs between these TFs (Fig. 2). Many studies have shown that ABA-independent and ABA-dependent pathways might converge at several unexpected points. This points of convergence represent transcriptional repressors and enhancers interacting indirectly or directly with $\mathrm{DRE} / \mathrm{C}$ repeat and $\mathrm{ABRE}$ and hence initiate synergistic interactions between ABA response and osmotic stress (Fig. 2).

The above mentioned TF families have been studied in detail in a number of important food crops and also in model plant systems including; Arabidopsis thaliana, Oryza sativa, Triticum aestivum, Sorghum bicolor, Vitis vinifera, Hordeum vulgare, Solanum tuberosum, and Brassica napus. Recent studies have shown the functions of abiotic stress-responsive TFs, and their potential roles to be used in future for purposes of molecular breeding and improvement of different crop varieties.

Much progress has been achieved in our understanding of transcriptional regulation, signal transduction, and gene expression in plant responses to abiotic stresses (Zhu et al., 2010). In rice for example, overexpression of a NAC TF encoding gene, $S N A C 1$ resulted in increased yields and increased tolerance to drought in transgenic plants (Hu et al., 2006). Overexpression of a Glycine soja NAC TF designated as GsNAC019 in transgenic Arabidopsis resulted in plants that were tolerant to alkaline stress at both the seedling and mature stages although the transgenic plants had reduced sensitivity to Abscisic acid (ABA) (Cao et al., 2017). Similarly, functional analysis of a Pyrus betulifolia NAC TF gene designated as PbeNAC1, revealed that this gene is involved in the regulation of cold and drought stress tolerance (Jin et al., 2017). Additionally, a chickpea (Cicer arietinum) stress associated TF, CarNAC4 was linked with reduced MDA content and water stress rates in response to salinity and drought stress respectively (Yu et al., 2016).

Ramakrishna et al. (2018) showed that overexpression of a finger millet bZIP TF gene EcbZIP17 in tobacco plants resulted in higher germination rate, increased biomass, and increased survival rate in the transgenic plants. Furthermore, the transgenic tobacco plants also showed increased seed yields compared to the control plants. Likewise, $\mathrm{Xu}$ et al. (2016) showed that transgenic Arabidopsis and soybean seedlings overexpressing a soybean bZIP TF designated as GmbZIP110 had improved salt tolerance, suggesting that GmbZIP110 functions as a positive regulator involved in salt stress tolerance. Functional analysis of GmbZIP110 in transgenic Arabidopsis revealed that this gene could bind to the ACGT motif and regulate many downstream target genes (Cao et al., 2017). Elsewhere, overexpression of an Arabidopsis bZIP TF designated as $A B F 3$ in transgenic alfalfa (Medicago sativa) under the command of a sweet potato oxidative stress-inducible promoter $S W P A 2$, resulted in improved growth under drought stress (Wang et al., 2016c). In hot pepper (Capsicum annuum), overexpression of a bZIP encoding gene $C a B Z 1$ in transgenic potato significantly improved dehydration stress tolerance without any detrimental effects on plant growth or yield (Moon et al., 2015).

Overexpression of OsMYB55, a rice MYB encoding gene in transgenic maize resulted in improved plant growth as well as decreased negative effects of drought and high temperature (Casaretto et al., 2016). Wei et al. (2017) demonstrated that CiMYB3 and CiMYB5 cloned from Cichorium intybus were both involved in the fructan pathway degradation in response to various

Peer] reviewing PDF | (2019:02:35201:1:2:REVIEW 9 May 2019) 
238

239

240

241

242

243

244

245

246

247

248

249

250

251

252

253

254

255

256

257

258

259

260

261

262

263

264

265

266

267

268

269

270

271

272

273

274

275

276

277

278

279

abiotic stresses. In banana (Musa paradisiaca), overexpression of an MYB TF gene designated as $M p M Y B S 3$ significantly improved tolerance to cold stress in transgenic plants (Dou et al., 2015). Elswhere, a MYB TF gene designated as MtMYBS from Medicago truncatula was able to enhance salt and drought tolerance in transgenic Arabidopsis by improving the primary root growth (Dong et al., 2017). Likewise, overexpression of GaMYB62L from cotton (Gossypium arboreum) in transgenic Arabidopsis resulted in enhanced drought tolerance (Butt et al., 2017).

The exogenous expression of AtDREB1A (Dehydration responsive element binding proteins) gene from Arabidopsis in transgenic Salvia miltiorrhiza resulted in plants with higher antioxidant activities and photosynthetic rates under drought stress (Wei et al., 2016). Elsewhere, overexpression of SbDREB2A from Salicornia brachita in transgenic tobacco resulted in improved growth and seed germination under hyperionic and hyperosmotic stresses (Gupta et al., 2014). Zhang et al. (2015) cloned SsDREB protein from Suaeda salsa and showed that this protein enhances the photosynthesis rate in transgenic tobacco plants under drought and salt stresses.

In the WYKY TF gene family, OsWRKY71 from rice was found to act as a positive regulator to cold stress tolerance by regulating several downstream genes like WSI76 and OsTGFR (Kim et al., 2016). VIGS (Virus-induced gene silencing) of GhWRKY6 gene from cotton (Gossypium hirsutum) led to increased sensitivity to various abiotic stresses in the silenced plants (Ullah et al., 2017). Elsewhere, SIDRW1 and SLWRKY39 which are WRKY TFs were found to confer both abiotic and biotic stress tolerance in tomato (Solanum lycopersicum) by activating both abiotic stress and pathogenesis-related downstream genes (Liu et al., 2014a; Sun et al., 2015).

TFs and regulons involved in abiotic stress regulation from other TF families have also been identified and described. For instance in Populus euphratica, exogenous expression of PeHLH35 belonging to the bHLH TF family resulted in significant improvement in water deficit tolerance through changes in several physiological processes such as stomatal density and transcription rate (Dong et al., 2014). In tomato, overexpression of a cycling Dof factor (CDF) TF designated as $C D F 3$ resulted in increased biomass production and higher yields in transgenic tomato plants under salt stress (Renau-Morata et al., 2017).

\section{TFs and the specific target genes involved in abiotic stress tolerance in maize}

\section{MYC/ MYB regulon}

The MYC (myelocytomatosis)/ MYB (myeloblastosis) families of TF proteins have diverse functions and are found in both animals and plants (Abe et al., 2003). Both MYB/ MYC TFs participate in the ABA-dependent pathway involved in abiotic stress signaling (Fig. 1). The first MYB TF gene in plants was identified in Maize and was designated as $C 1$, it codes for a c-MYB like TF that is involved in the biosynthesis of anthocyanin (Paz-Ares et al., 1987). In the MYB family, each TF consists of an MYB domain containing 1 to 3 imperfect repeats and is made up of around 52 amino acid residues with a helix-turn-helix $(\mathrm{HTH})$ conformation which interposes inside the major grooves of DNA (Yanhui et al., 2006). Both MYB and MYC TFs are usually involved in making up the common regulons known as the MYB/ MYC regulons (Gahlaut et al., 2016). 
280 In the maize genome, Du et al. (2013) reported 72 MYB related proteins. Chen et al. (2017) 281 analyzed the expression profiles of 46 MYB genes from maize, in response to various abiotic 282 stresses and found 22 genes that responded to the different stress conditions. Additionally, 16 of 283 these genes were induced in response to a minimum of two stresses. These results suggesting that 284 these genes could take part in signal transduction pathways involved in abiotic stress responses. Additionally, the function of $Z m M Y B 30$ which was significantly up-regulated under drought, salt, and ABA stresses was further analyzed (Table. 1). Exogenous expression of ZmMYB30 in Arabidopsis stimulated tolerance to salt and elevated the expression of eight abiotic stress corresponding genes (ABF3, ATGolS2, AB15, DREB2A, RD20, RD29B, RD29A, and MYB2) enabling transgenic plants to be more tolerant to adverse environmental conditions (Table. 1). Moreover, another six genes (RD22, RbohD, P5CS1, RAB18, RbohF, and LEA14) were either unchanged or slightly elevated in the transgenic Arabidopsis plants.

Another maize MYB TF, ZmMYB31 was found to repress the biosynthesis of sinopoylmalate leading to increased sensitivity to UV irradiation and dwarfism in transgenic plants (Fornale et al., 2010). Furthermore, $\mathrm{ZmMYB31}$ activated a number of stress-responsive genes $(\mathrm{ZmF} 5 \mathrm{H}, \mathrm{C} 3 \mathrm{H}$, ZmActin and ZmCOMT) in vivo in maize, and 4CL1 and COMT genes in transgenic Arabidopsis. The roles of maize MYB related genes in response to drought stress were examined based on microarray data (Dash et al., 2012; Du et al., 2013). On the maize 18k GeneChip, 26 probe sets were shown to correspond to $32 \mathrm{MYB}-$ related genes (whereby five probes represented one gene). Further analysis of this highly similar sequence data revealed that the majority of the MYBrelated genes were expressed at low levels, although their expression was in response to a specific stress. Elsewhere, gene expression analysis between two maize varieties, a drought sensitive (Ye478) variety, and a drought tolerant (Han21) variety was found to be very similar (Du et al., 2013). For instance, four CCA1-like/ R-R genes (ZmMYBR49, ZmMYBR19, ZmMYBR56, and ZmMYBR28), six TBP-like genes (ZmMYBR55, ZmMYBR45, ZmMYBR47, $Z m M Y B R 31, Z m M Y B R 26$, and ZmMYBR07) and a single TRF-like gene (ZmMYBR41) were all elevated in response to drought stress. Expression analysis of $Z m M Y B R 37$ an I-box-like gene, and five CCA1-like/ R-R genes (ZmMYBR63, ZmMYBR44, ZmMYBR27, ZmMYBR18, and $Z m M Y B R 03)$, showed that these genes were highly down-regulated in response to drought stress. Although recovery of all these genes above was observed after re-watering (Table. 1). Similarly, a maize R1-type TF that is encoded by $Z m M Y B-R 1$ gene was activated by cold, exogenous ABA, drought, heat and high salinity (Liu et al. 2012). Functional analysis of ZmMYB-R1 in different tissues revealed it first reached its maximum levels in the leaves and later it was detected in the roots and stems.

In the model plant Arabidopsis, MYB and MYC TFs were found to accumulate in plant tissues following the accumulation of ABA (Lata et al., 2007). Seven Arabidopsis MYB TF genes namely AtMYBCDC5, AtMYB77, AtMYB73, AtMYB44, AtMYB6, AtMYB7, and AtMYB4 were all strongly expressed in all organs, in response to several abiotic stresses (Yanhui et al., 2006). Functional analysis of two MYB/ MYC genes, (AtMYC2 and AtMYB2) in transgenic Arabidopsis revealed that the TF proteins encoded by these two genes can bind to the promoter regions of several ABA or jasmonic-acid (JA) inducible genes. For example, AtADH1 and RD22 thus making the transgenic Arabidopsis plants ABA-responsive and more tolerant to both drought and osmotic stress (Abe et al., 2003).

323 Taken together, all the above findings suggest that $M Y B$ genes could be engineered in crops 324 leading to activation of general pathways involved in abiotic stress responses in plants. For 
instance, overexpression of $O s M Y B 55$, a rice R2R3-MYB TF significantly improved rice plants tolerance to extreme temperatures, and this was directly linked with improved amino acid metabolism (El-kereamy et al., 2012). Additionally, these findings will facilitate our understanding of gene regulation by MYB TFs, thus leading to the development of new abiotic stress tolerant crop varieties. Finally, Phylogenetic, functional and structural analyses revealed that most homologous MYB proteins that possess conserved domains have similar activities and functions in divergent plant species. Although a lot of information is available on the molecular functioning of MYB TFs in abiotic stress responses, deciphering the downstream and upstream events in MYB TFs in abiotic stress responses remains an immense undertaking.

\section{The AP2/EREBP regulons}

The AP2/EREBP (ethylene-responsive element binding protein) family is made up of a large group of plant specific TFs that are characterized by the presence of a highly conserved AP2/ethylene-responsive element binding factor (ERF). The ERF interacts directly with GCC box and/or DRE/C-repeat element (CRT) at the promoter site of downstream target genes (Reichmann and Meyerowitz, 1998). AP2/EREBP TFs play vital roles in stress responses and developmental processes such as cell proliferation, plant hormone responses, and biotic and abiotic stress responses (Sharoni et al., 2011). Based on the similarity and number of AP2/ERF domains, AP2/EREBP TFs are grouped into four main subfamilies: ERF, RAV (related to AB13/VP1), DREB and AP2 (Apetala 2) (Sharoni et al., 2011). Among these four, the DREB subfamily has been extensively studied due to the roles its TFs play in plant biotic and abiotic stress responses.

Dehydration responsive element binding proteins (DREBs) play a significant role in the ABAindependent pathways that are responsible for the activation of abiotic stress-regulatory genes (Lata et al., 2007). DREB TFs are made up of one AP2/ERF DNA binding region, which binds to the cis-acting element DRE composed of TACGACAT (a 9bp core sequence) and is present in the promoters of Abiotic stress-responsive genes (Gahlaut et al., 2016). The existence of this cisacting element (CRE) has been recorded in several abiotic stress-responsive genes for example $R D 29 B$ and $R D 29 A$ in Arabidopsis (Yamaguchi-Shinozaki and Shinozaki, 1994). C-repeat (CRT) cis- acting elements consisting of the A/GCCGAC motif and which are similar to DREBs, have been identified in the promoter regions of cold-responsive genes in Arabidopsis, whereby the CRT elements bind to the TF CBF (CRT binding factor) in response to cold stress (Saleh et al., 2005). In Arabidopsis for example, exogenous overexpression of AtDREB1/CBF led to cold, drought, and high salinity tolerance in transgenic plants. These findings clearly suggest that DREBs/CBFs TFs have the potential to target multiple stress-responsive candidate genes in the plant genomes (jaglo-Ottosen et al., 1998; Kasuga et al., 1999).

In maize, the role of DREB TFs has been investigated by adopting both molecular and genetic analyses. For example, $Z m D R E B 1 A$ was activated by cold stress and moderately elevated by high-salinity stress in maize seedlings (Qin et al., 2004) (Table. 1). Over-expression of ZmDREB1A in transgenic Arabidopsis led to induced over-expression of abiotic stress-activated genes giving rise to plants with enhanced tolerance to extreme drought and freezing stresses (Table. 2). Investigations were done to ascertain whether $Z m D R E B 1 A$ could induce other genes in the dehydration and/or cold pathways of wild-type plants. The results revealed that expression levels of KIN1, KIN2, and COR $15 A$ were all highly up-regulated in the $35 \mathrm{~S}: \mathrm{ZmDREB} 1 \mathrm{Aa}$ 
transgenic line under normal conditions when compared to the wild-type plants. Expression analysis of $R D 17, E R D 10$ and $R D 29 A$ showed that these genes were slightly up-regulated in the 35S:ZmDREB1Aa transgenic line. The above results showed that ZmDREB1A induces both ABA-independent genes like (COR15A, KIN1, and KIN2) and ABA-dependent genes like (RD17, ERD10, and RD29A). Therefore, it was concluded that this gene might affect the expression of dehydration and cold-responsive genes in both the ABA-independent and ABAdependent pathways. Likewise, another DREB TF gene ZmDBP3 was highly induced by cold and moderately induced by salinity stress (Wang and Dong, 2009) (Table. 1). Over-expression of this gene in transgenic Arabidopsis led to improved tolerance to both cold and drought stresses (Table. 2).

Natural variations present in the promoter region of another maize DREB TF gene ZmDREB2, lead to drought tolerance in maize (Liu et al., 2013) (Table. 1). In transgenic Arabidopsis, overexpression of $Z m D R E B 2$ resulted in plants with enhanced tolerance to drought. Elsewhere, qRTPCR analysis of maize leaves revealed that expression of $Z m D R E B 2 A$ was induced by dehydration, heat and cold stress (Qin et al., 2007). Overexpression of $Z m D R E B 2 A$ in transgenic Arabidopsis resulted in dwarf plants with enhanced tolerance to drought and heat stresses. Microarray analysis of these transgenic Arabidopsis plants identified a number of genes associated with detoxification and heat shock for example $R D 29 B$ and At5G03720. Moreover, five genes coding for late embryogenesis abundant (LEA) proteins (LEA14, At1g52690, At3G53040, At3G15670, and At2G36640) in addition to a metabolism associated gene AtGoIS3, were all up-regulated under different stress treatments in the transgenic lines (Table. 1). Elsewhere, functional analysis of $Z m D B F 3$ showed that this TF gene was activated by drought, high temperature, salt, cold and abscisic acid (ABA). However, no significant difference was noted under methyl jasmonate (MeJA) and salicylic acid (SA) (Zhou et al., 2016). Ectopic expression of $Z m D B F 3$ in yeast (Saccharomyces cerevisiae) resulted in a higher survival rate during exposure to $\mathrm{KCI}, \mathrm{Na}_{2} \mathrm{CO}_{3}, \mathrm{NaHCO}_{3}, \mathrm{NaCl}$, PEG 6000, sorbitol, and freezing temperatures. Moreover, exogenous expression of $\mathrm{ZmDBF3}$ in transgenic Arabidopsis considerably improved tolerance to drought, freezing and salt stresses (Table. 2). These findings, suggest that $Z m D B F 3$, a novel maize DREB TF may have similar functions to a regulatory factor taking part in abiotic stress response pathways. Similarly, overexpression of $\mathrm{ZmDBP4}$ in Arabidopsis resulted in transgenic plants with improved cold and drought stress tolerance (Wang et al., 2011) (Table. 2). Analysis of the promoter region of $\mathrm{ZmDBP} 4$ identified cis-acting elements which responded to abiotic stresses, suggesting that $\mathrm{ZmDBP4}$ encodes a functional factor that plays an important role in the control of multiple abiotic stress responses in maize. Elsewhere, mRNA accumulation analysis profiles of two DRE-binding proteins ( $D B F 1$ and $D B F 2$ ) in maize seedlings revealed that $D B F 1$ was induced during embryogenesis and in response to drought, $\mathrm{ABA}$, and $\mathrm{NaCl}$ treatments (Kizis and Investigacio, 2002).

DREB TFs are versatile when it comes to abiotic stress regulation. Recently, numerous studies have been done to understand the roles DREB TFs play in abiotic stress responses and to reveal the mechanisms involved in their transcription and post transcriptional regulation. Collectively, these studies suggest that DREB TFs can be potential candidates for abiotic stress tolerance, although these studies have not addressed the vital question of whether DREB TFs can improve the yield of engineered crops under stress. Many DREB homologues have been identified and isolated from different plant species, especially from plant species with exceptional tolerance to different abiotic stresses. Thus, the focus now is to evaluate the existing methods of yield 
414 analyses under different stress conditions and to assess transgenic plants in actual field 415 conditions.

416

\section{NAC TFs and regulons}

418

419

420

421

422

423

424

425

426

427

428

429

430

431

432

433

434

435

436

437

438

439

440

441

442

443

444

445

446

447

448

449

450

451

452

453

454

455

456

457

The TF members in the NAC family, (ATAF, CUC, and NAM) represent one of the largest plant-specific TFs (Ooka et al., 2003). In the main crop species, a large number of NAC TFs have been analyzed and sequenced at the genome-wide level. These include 151 members in rice and 117 in Arabidopsis (Nuruzzaman et al., 2010), 204 members in the Chinese cabbage (Liu T.K et al., 2014b) and 152 members in maize (Shiriga et al., 2014). The TFs belonging to the NAC family share a greatly conserved N-terminus made up of 150-160 amino acid residues, constituting a DNA-binding domain that carries five sub-domains (A-E) and a varying Cterminal (Hu et al., 2008; Ooka et al., 2003). The NAC genes and their constituent cis-acting elements (NARCs) make up the NAC regulons, which further provide vital examples of finely characterized collaboration between a single $\mathrm{TF}$ and one or more cis-acting elements that associate in response to multiple stresses (Christianson et al., 2010). The roles of NAC TFs in plants have been extensively studied in rice and Arabidopsis. In Arabidopsis for example, an ERD1 (early dehydration stress 1) gene was activated by a number of NAC TFs including $A N A C 055, A N A C 019$, and $A N A C 072$ (Tran et al., 2007). A rice NAC TF designated as OsNAM, was found to regulate the activation of five genes (OsAH, OsCESA, OsMtN3, OsGdpD, and $O s G D P$ ) in response to drought (Dixit et al., 2015). Several NAC TFs utilize the NACRS motif in plants, for instance $S N A C 2$ and ENAC1 found in rice (Sun et al., 2012) and $A N A C 055$, ANAC072 and ANAC019 found in Arabidopsis (Tran et al., 2004).

In maize, several NAC TFs involved in abiotic stress regulatory pathways have been isolated, cloned and characterized. Recently, expression analysis of ZmSNACl in maize seedlings revealed that this TF gene was strongly induced by high salinity, drought, ABA treatment, and low temperature, although it was down-regulated in response to salicylic acid (SA) treatment (Lu et al.,2012). Over-expression of ZmSNACl in transgenic Arabidopsis led to increased hypersensitivity to osmotic stress and ABA as well as enhanced tolerance to dehydration stress at the germination phase (Table. 2). These results suggest that ZmSNAC1 acts as a multiple stress responsive TF, positively modulating abiotic stress tolerance in maize. Elsewhere, Shiriga et al. (2014) identified 11 NAC TF genes in maize that were induced by various abiotic stresses. This prediction was confirmed when these genes were differentially expressed in response to drought stress. Four genes, ZmNAC45, ZmNAC72, ZmNAC18, and ZmNAC51 were all up regulated in the drought-tolerant maize genotypes and down-regulated in the drought susceptible genotypes. Recently, seven ZmNTL, NAC TFs genes (ZmNTL1, ZmNTL2, ZmNTL3, ZmNTL4, ZmNTL5, ZmNTL6, and ZmNTL7) were analyzed in maize seedlings and all seven genes were found to be strongly expressed in the stem and roots and down-regulated in the leaves when the plants were exposed to hydrogen peroxide and/or ABA treatments. Exogenous expression of ZmNTL1, ZmNTL2, and ZmNTL5 in transgenic Arabidopsis led to increased tolerance to hydrogen peroxide in transgenic plants (Wang et al., 2016a). Overexpression of ZmNAC55 in transgenic Arabidopsis resulted in plants which were hypersensitive to ABA at the seedling stage but showed enhanced resistance to drought when compared to the wild-type control seedlings (Mao et al., 2016). Additionally, twelve stress-responsive genes (RD20, NCED3, ZAT10, ANAC019, LEA14, RD29B, RD29A, DREB2A, RD17, RD26, RAB18, and PP2CA) were all up regulated in 
458

response to drought stress in the transgenic lines (Table. 1). Expression profiles of ZmNAC55 in maize revealed that this gene was induced by high salinity, drought, ABA and cold stress.

Elsewhere, seven NAC TF genes analyzed in maize seedlings (Zma001259, Zma000584, Zma029150, ZmSNAC052, Zma003086, Zma054594, and Zma006493) were all found to be up regulated in response to salt stress in all tissues (Lu et al., 2015). In response to PEG treatment, three of the above-mentioned genes, namely Zma006493, Zma003086 and Zma000584 were significantly up regulated in the roots only, while Zma001259, Zma029150, Zma000584, and Zma054594 were all strongly expressed in both the roots and shoots. Five genes, Zma054594, Zma000584, Zma001259, Zma003086, and ZmSNAC052 were activated by cold stress although in varying degrees. In conclusion, due to the strong expression in response to ABA treatments, these seven genes could play a vital role in the ABA-dependent signaling network in maize.

Numerous advancements in NAC TFs functional studies have been achieved over the past few years. However, most of these studies are related to the involvement of NAC TFs in biotic stress responses. To achieve a deeper understanding of NAC TFs in abiotic stress responses, it is of vital importance to identify the main components of signal transduction pathways that interact with these TFs. Utilizing data obtained from microarray analyses could help in the direct determination of specific NAC DNA- binding sites on a global scale under different abiotic stress conditions.

Finally, numerous studies have demonstrated the use of stress-responsive NAC TFs in the improvement of abiotic stress tolerance in crops by genetic engineering. In view of the specificity of NAC TF in multiple stress responses, NAC TFs that are induced by multiple abiotic stresses are promising candidates in the engineering of plant varieties with improved multiple stress tolerance (Shao et al., 2015). Moreover, field evaluation of engineered crops containing NAC TF genes and efficient promoters, for reducing detrimental effects triggered by overexpression of some NAC genes must be considered (Rushton et al., 2008).

\section{bZIP TFs: AREB/ABF regulon}

The ABA-responsive element (ABRE; PyACGTGG/TC), is a conserved cis-acting element bound by the basic Leucine Zipper Domain (bZIP) TFs (Loredana et al., 2011). The ABRE was first established on the promoter region of ABA-activated genes by (Giraudat et al., 1994). The bZIP TFs, belong to one of the largest and diversified TF families in plants. They are categorized into ten subfamilies based on the presence of extra conserved motifs and the basic region sequence similarities (Perez-Rodrigues et al., 2010). AREB/ABF TFs are characterized by a strongly conserved bZIP domain made up of two structural components [a leucine (Leu) zipper and a basic region], the leucine (Leu) zipper is composed of heptad repeats of Leu and/ or other heavy hydrophobic amino acid residues and controls hetero- and or homodimerization of the bZIP proteins. The basic region is composed of 16 amino acids with the indistinguishable N-x7$\mathrm{R} / \mathrm{K}-\mathrm{x} 9$ motif and is responsible for DNA binding and nuclear localization (Jakoby et al., 2002). The bZIP TFs, which are part of the AREB/ABF regulons, give an excellent example of interactions involving stress-responsive genes and TFs carrying the cis-acting element (ABRE). In maize, a bZIP TF gene $A B P 9$ that has the ability to bind to the AREB2 motif located in the Cat1 promoter region was activated by drought, salt, $\mathrm{H}_{2} \mathrm{O}_{2}$, and ABA (Zhang et al., 2011). Exogenous expression of $A B P 9$ in Arabidopsis led to significant tolerance to freezing, salt, 
501 oxidative stress and drought in transgenic plants. Transgenic Arabidopsis plants also showed 502 enhanced sensitivity to exogenously supplied ABA during stomatal closure, seed germination, 503 and root growth. Furthermore, transgenic plants expressing $A B P 9$ showed reduced levels of 504 oxidative cellular damage, reduced cell death and reduced levels of ROS.

505 More recently, Wang et al. (2017) demonstrated that $A B P 9$ enhanced salt and osmotic stress 506 tolerance in transgenic cotton plants. Overexpression of $A B P 9$ resulted in elevated transcripts of 507 several stress responsive-genes (GhNCED2, GhDBP2, GhZFP1, GhHB1, GhSAP1, and $508 G h E R F 1$ ) in the transgenic cotton plants in response to salt stress (Table. 2). Additionally, 509 transgenic plants were shown to have higher germination rates, and improved root systems in a 510 greenhouse setting and reduced stomatal density and stomatal aperture in a growth room. Finally, 511 the relative water content (RWC) and survival rate of the transgenic plants was significantly 512 higher compared to the control plants in response to drought. Wang et al. (2012) demonstrated 513 that expression of ZmbZIP60 was highly activated by a wide range of stresses including ABA, 514 high salinity, tunicamycin treatment and dehydration (Table. 1). In the wild-type Arabidopsis, 515 over-expression of ZmbZIP60 resulted in plants with enhanced tolerance to dithiothreitol (DDT) 516 stress. Furthermore, Li et al. (2018) discovered a major QTL governing heat-induced ZmbZIP60 517 expression and deduced that the upstream region of ZmbZIP60 plays a vital role in regulating 518 responses to heat stress in maize.

519 Similarly, Ying et al. (2011) cloned and characterized a maize bZIP TF gene designated as 520 ZmbZIP72, which was induced by drought, ABA and high salinity stress (Table. 1). ZmbZIP72 521 was differentially expressed in various organs in maize. Overexpression of ZmbZIP72 in 522 transgenic Arabidopsis led to enhanced tolerance to drought, partial tolerance to salinity and 523 hypersensitivity to osmotic stress and ABA treatment. Furthermore, the transgenic Arabidopsis 524 plants also showed enhanced expression of several ABA-inducible genes including (RAB18, 525 HIS1-3, and $R D 29 B$ ). Elsewhere, microarray analysis of two specific maize inbred lines, a 526 drought-sensitive Ye478 line, and a drought tolerant Han21 line revealed that 22 ZmbZIP genes might play a critical role in drought tolerance (Wei et al., 2012a). In the same report, ZmbZIP37 an orthologous gene of two rice genes $O s b Z I P 72$ and $O s b Z I P 23$ that both play vital roles in drought tolerance and ABA response in rice, was found to be up-regulated in response to drought stress in maize. Similarly, cloning and characterization of a bZIP TF gene ZmbZIP17 from the Han21 maize inbred line revealed that this gene was up regulated in response to drought (Jia et al., 2009). Real-time PCR analysis revealed that ZmbZIP17 was highly up regulated in response to heat, salinity, drought, and ABA stresses immediately, suggesting that this gene represents an early responsive gene that reacts to various abiotic stresses. Elsewhere, expression analysis of two maize bZIP TF genes ZmbZIP107 and ZmbZIP54 revealed that these two genes were highly elevated in a lead tolerant maize line when compared to a lead sensitive line in response to different treatments of lead (Zhang et al., 2017) (Table. 1). Recently, Ma et al. (2018) demonstrated that ZmbZIP4 was induced by drought, cold, high salinity, ABA, and heat in maize seedlings. Overexpression of ZmbZIP4 led to an improved root system, increase in the number of lateral roots, and longer primary roots in transgenic maize. Additionally, genome-wide analysis of $\mathrm{ZmbZIP} 4$ target genes by immunoprecipitation sequencing, unearthed a number of downstream stress response genes that were positively regulated by ZmbZIP4. These downstream target genes included ZmRD21, ZmLEA2, ZmRD20, ZmGEA6, ZmNHX3, and $Z m R A B 18$. Collectively, these results suggested that $Z m b Z I P 4$ is a positive regulator of abiotic stress response that takes part in root development in maize. 
546 In conclusion, the promoter region of each abiotic stress responsive gene might carry a single or 547 several proximal or distal coupling elements (CE) for instance, CE 3 and CE1 which activate the 548 expression of abiotic stress-responsive genes. In addition, Shen et al. (1996) identified CEs in 549 Hordeum vulgare that form an abscisic acid response complex (ABRC), which could be a 550 necessary component in triggering ABA-mediated gene expression. Collectively, the above 551 reports confirmed the participation of bZIP TFs in the ABA signaling pathway. These findings 552 could be useful in the future development of better genotypes with improved tolerance to various abiotic stresses (Todaka et al., 2015). An accurate understanding of the functions of bZIP TFs in crops will require an accurate mapping of the location of bZIP genes in the different plant organs.

556

557

558

559

560

561

562

563

564

565

566

567

568

569

570

571

572

573

574

575

576

577

578

579

580

581

582

583

584

585

586

587

588

589

\section{WRKY TFs and WRKY regulons}

WRKY proteins represent the largest superfamily of TFs, which are specific to plants. WRKY TFs control plant growth and development and spur tolerance against both abiotic and biotic stresses (Tripathi et al., 2014). WRKY TFs are usually identified by a WRKY domain made up of 60 amino acid residues, and contains a highly conserved WRKYGQK sequence followed up by a zinc- finger motif. The WRKY domain shows a strong binding affinity for a cis-acting element known as W-box (TTGACC/T), which is present in a number of abiotic stress responsive genes (Rushton et al., 2010; Ulker and Somssich, 2004).

Several WRKY TFs involved in abiotic stress tolerance have recently been reported in maize. For example, functional analysis of ZmWRKY33 under different abiotic stresses, revealed that this gene was activated by cold, dehydration, ABA and salt treatments (Li et al., 2013). Overexpression of $Z m W R K Y 33$ in transgenic Arabidopsis led to the activation of two stress-activated genes $(R D 29 A$ and $D R E B 1 B)$, which were both up-regulated resulting in enhanced salt tolerance in the transgenic plants (Table.1). The above-mentioned results strongly suggest that this maize WRKY TF plays a vital role in abiotic stress regulation in maize. Elsewhere, Wang (2013) demonstrated that exogenous over-expression of ZmWRKY44 in transgenic Arabidopsis resulted in plants that were moderately sensitive to $\mathrm{NaCl}$ stress. In maize seedlings, ZmWRKY44 was induced by high temperature, salt stress, ABA, and hydrogen peroxide treatments. Recently, $Z m W R K Y 17$ was cloned, characterized and its expression was analyzed in maize seedlings (Cai et al., 2017) (Table. 1). The results showed ZmWRKY17 was induced by ABA, salt and drought stresses. Additionally, constitutive expression of this gene in transgenic Arabidopsis led to a striking reduction in tolerance to salt stress, as confirmed by the physiological assays performed on relative electrical leakage, malondialdehyde (MDA) content, cotyledons greening rate and root growth. Still in the same study, RNA-Seq analysis showed that eight stress-related genes (DREB1F, KIN1, bHLH92, RD29A, RD29B, NAC019, RD22, and MYB101) were significantly up-regulated in the wild-type plants when compared to the transgenic plant lines in response to salt stress. However, expression of NCED5 was higher in transgenic plants under the same stress. Together, these results give a strong indication that $Z m W R K Y 17$ may function as a negative regulator in response to drought stress in maize. This could be due to elevated levels of ABA ensuing as a direct response to salt stress through the ABA signaling system. Wei et al. (2012b) compared the expression profiles of 31 WRKY genes in two maize lines, a drought-sensitive Ye478 line and a drought tolerant Han21 line. The results showed that the expression of the WRKY genes in the drought-tolerant Han21 line changed less, and the seedlings recovered faster 
590

591

592

593

594

595

596

597

598

599

600

601

602

603

604

605

606

607

608

609

610

611

612

613

614

615

616

617

618

619

620

621

622

623

624

625

626

\section{7}

628

629

630

631

when re-watered, as opposed to the drought-sensitive Ye478 seedlings. In the same study, the expression of $Z m W R K Y 115$ was decreased as a direct result of drought stress. Elsewhere, qRTPCR expression analysis showed that ZmWRKY58 was activated by salt, drought and ABA treatments (Cai et al., 2014) (Table. 1). Constitutive expression of ZmWRKY58 in transgenic rice led to delayed germination and constrained post-germination growth and development. However, transgenic seedlings over-expressing ZmWRKY58 reported increased tolerance to both salt and drought stresses (Table. 2). Similarly, Wang et al. (2018a) identified a WRKY TF gene named ZmWRKY40 (Table. 1). A number of stress-related transcriptional regulatory factors were located in the promoter region of this gene. In maize, $Z m W R K Y 40$ was induced by high salinity, drought, abscisic acid (ABA) and high temperature. Overexpression of ZmWRKY40 in Arabidopsis led to enhanced drought tolerance in the transgenic plants. Additionally, overexpression of $Z m W R K Y 40$ induced the expression of three stress-responsive genes DREB2A, STZ and RD29A in transgenic Arabidopsis. Recently, the expression of ZmWRKY106, a member of the WRKYII group was found to be induced by high temperature, drought, and exogenous ABA treatment, but was weakly induced by salinity (Wang et al., 2018c). Overexpression of ZmWRKY106 in transgenic Arabidopsis led to improved tolerance to heat and drought. Additionally, ZmWRKY106 positively regulated the expression of several stress response genes including RD29A, CuZnSOD, $D R E B 2 A$, and NCED6. The above results strongly indicate ZmWRKY106 may play an important role in the abiotic stress response pathways in maize by regulating stress-related genes.

In the model plant Arabidopsis, two WRKY genes WRKY 60 and WRKY 18 were found to regulate ABA signaling positively while one WRKY gene $W R K Y 40$ negatively regulated ABA signaling. These three WRKY genes mentioned above, bind to the promoter region of several genes including some TFs genes like (DREB1A/CBF3, $A B I 5$, and $D R E B 2 A)$, and several stressregulated genes like (COR47 and $R D 29 A$ ) in the process controlling their expression (Shang et al., 2010; Chen et al., 2010).

WRKY TFs have been identified as promising candidates for crop improvement due to the strict regulations involved in the identification and binding of these TFs to the downstream target promoter regions (Phukan et al., 2016). Taken together, all the above insights highlight the multiple stress responses and diverse regulation of WRKY TFs in maize and other crops.

\section{Other TFs and their Regulons}

Apart from the five main TF families described above, other TF families take part in diverse roles in plants including, regulating responses to both abiotic and biotic stresses, and various growth and development processes. Recently, extensive research has uncovered stress-mitigating roles of a number of TFs whose responses to abiotic stressors were previously unknown in maize. Three of these TF families are briefly described below.

\section{Homeodomain-leucine zipper I (HD-ZIP) I}

HD-Zip proteins represent a large TF family that is specific to plants. HD-Zip proteins have been cloned and characterized in several important crops and some model plants such as rice, Arabidopsis, tomato and sunflower (Johannesson et al., 2003; Lin et al., 2008; Agalou et al., 2008; Manavella et al., 2006). HD-Zip proteins are characterized by a DNA-binding

Peer] reviewing PDF | (2019:02:35201:1:2:REVIEW 9 May 2019) 
632 homeodomain (HD) and a neighboring leucine zipper (Zip) motif whose function is to mediate 633 protein dimerization (Ariel et al., 2007). HD-Zip proteins belonging to the subfamily I are 634 believed to take part in the majority of plant responses to abiotic stresses (Ariel et al., 2007). In 635 Arabidopsis for example, analysis of four HD-Zip TFs (ATHB6, ATHB7, ATHB5 and ATHB12) 636 revealed that these genes were up-regulated or repressed by either ABA or drought stress 637 (soderman et al., 1996; Lee et al., 2001; Soderman et al., 1999; Johannesson et al., 2003). These 638 results suggest that these four genes may play a vital role in the regulation of abiotic stress 639 regulatory networks in plants.

640 In maize, Zmhdz10 was the first HD-Zip TF to be isolated and characterized (Zhao et al., 2014). 641 Expression of this gene was activated by abscisic acid (ABA) treatment and salinity stress 642 (Table. 1). Exogenous over-expression of $Z m h d z 10$ in transgenic rice resulted in improved 643 tolerance to salt and drought stress and enhanced sensitivity to ABA. Furthermore, the transgenic 644 plants had elevated levels of proline and reduced malondialdehyde (MDA) content when 645 compared to the wild-type plants (Table. 2). Transgenic Arabidopsis plants over-expressing $646 \mathrm{Zmhdz} 10$ exhibited strong tolerance to salt and drought stresses, at the same time, expression 647 patterns of several ABA-responsive genes namely (ABI1, RD29B, P5CS1, and RD22) were 648 altered. The above results give a strong indication that $Z m h d z 10$ serves as a transcriptional 649 regulator that can positively regulate both salt and drought stress tolerance in the ABA650 dependent pathway in plants. Recently, Qing and Wei (2018) isolated and characterized a maize 651 HD-ZIP TF designated as Zmhdz12. Tissue expression analysis revealed that this TF was 652 strongly expressed in the leaves compared to other tissues. In transgenic Arabidopsis, Zmhdz12 653 was activated by drought as observed when the drought resistant transgenic lines were compared 654 to the wild-type lines. Similarly, expression status of $17 \mathrm{Zmhdz}$ I genes from maize ( $\mathrm{Zmhdzl}$ to $655 Z m h d z 17)$ revealed that all these genes were either repressed or up-regulated due to drought 656 stress (Zhao et al., 2011). Additionally, many of the genes above belonging to the same subgroup 657 in the phylogenetic tree, showed similar patterns of expressions. Elsewhere, ZmHDZ4 was 658 isolated and characterized in maize for its role in drought stress tolerance (Wu et al., 2016). 659 Overexpression of $\mathrm{ZmHDZ4}$ in transgenic rice resulted in plants with enhanced tolerance to 660 drought.

661 In conclusion, it is worth noting that HD-Zip proteins play crucial roles in cuticle formation, so 662 they might be involved in abiotic stress tolerance and protection against plant pathogens (Chew 663 et al., 2013). In addition, the roles described above make HD-Zip TFs ideal candidates for 664 genetic engineering in maize and other major crops. Although more in-depth studies are needed 665 in order to ascertain the function of individual HD-Zip family members in response to various 666 abiotic stresses.

667

668

669

670

671

672

673

674

675

\section{Heat Shock Proteins (HSPs)}

All organisms are composed of an evolutionarily conserved, fast cellular defense system known as heat shock (HS) response, which regulates various reactions associated with heat stress and a variety of chemical stressors (Lin et al., 2011). HSPs were first discovered in the salivary glands of Drosophila in response to heat shock (Ashburner and Bonner, 1979). HSFs family members function by binding to the promoter of chaperones referred to as heat shock proteins. HSF TFs have a $3 \mathrm{~N}$-terminal section and a C-terminal section in addition to leucine amino acid (Schuetz et al., 1991). HSPs can be categorized into six main families, (Hsp90, Hsp40, Hsp90, Hsp60, 
676 Hsp70, and Hsp110) based on their molecular sizes (Wang et al., 2004). HSPs in plants were first 677 characterized in tomato (Scharf et al., 1990), and since then more HSFs have been reported in 678 other plants such as Arabidopsis, rice, sunflower and wheat (Hubel and Schoffl, 1994; 679 Yamanouchi et al., 2002; Almoguera et al., 2002; Shim et al., 2009). A survey recently reported 680 that there are at least 24 HSFs in Brachypodium, 21 in Arabidopsis, 30 in maize, 25 in rice, 52 in 681 soybeans and 27 in tomatoes (Scharf et al., 2012). In the model plant Arabidopsis, a HsfA2 682 mutant displayed tolerance to osmotic stress, salt, and heat stresses, suggesting that this gene is 683 involved in several abiotic stress response networks and pathways (Ogawa et al., 2007).

684 Few HSPs gene have been isolated and characterized in maize. Jinhui et al. (2015) isolated and 685 characterized a Hsp70 gene named ZmERD2 (Early Responsive to Dehydration 2) from maize 686 (Table. 1). Expression patterns of ZmERD2 revealed that this gene was induced by cold, high salinity, dehydration, heat stress, and PEG but was not induced by abscisic acid (ABA). Further expression analysis revealed $Z m E R D 2$ was instantly activated at $42^{\circ} \mathrm{C}$ and its peak was reached after 1 hour of exposure to heat stress. Elsewhere, expression patterns of 22 Hsf genes from maize showed that these genes were differentially expressed when subjected to heat stress (Lin et al., 2011). Further analyses from this study revealed that ZmHsfA2 subclass in maize has close relations with heat shock response. This is after three HsfA2 genes (ZmHsf-17, ZmHsf-01, and $\mathrm{ZmHsf-04)}$ were strongly expressed in response to heat stress. In addition, six more genes were highly up-regulated in response to heat stress (ZmHsf-03, ZmHsf-01, ZmHsf-23, ZmHsf-24, $\mathrm{ZmHsf-04}$, and ZmHsf-25). These results pointing to the specific roles these genes play in maize in response to heat stress. Li et al. (2015) recently cloned a maize HSF designated as $\mathrm{ZmHsf06}$ from maize and transformed it in Arabidopsis thaliana. Expression analysis of the transgenic plants over-expressing $\mathrm{ZmHsf06}$ revealed that this gene was induced by drought and heat stress (Table. 2). The above results were confirmed by biochemical and physiological evidence that showed that the transgenic plants displayed longer axial root length, higher seed germination rate, elevated levels of chlorophyll in leaves as well as reduced osmotic potential (OP) and malondialdehyde (MDA) content when compared to the wild-type plants. Based on the above results, it's evident $\mathrm{ZmHsf06}$ could have future potential use in molecular breeding in maize as well as other crops for improved drought and heat stress tolerance.

Collectively, it is important to mention that HSPs have been shown to have a close association with reactive oxygen species (ROS), meaning that plants have gained a stronger level of ROS regulation throughout the course of evolution (Banti et al., 2010). Therefore, understanding the roles played by HSPs in plant responses to abiotic stresses will be useful in the engineering of abiotic stress tolerant crop varieties. HSP have been studied and characterized in a number of important crop varieties as mentioned above, although their functional plasticity and genome sequence data is still limited (Echevarria-Zomeno et al., 2016).

\section{NF-Y Transcription Factors}

Nuclear factor $\mathrm{Y}$ also referred to as $\mathrm{CBF}$ (CCAAT binding factor) or heme activator protein (HAP), is a complex made up of three subunits NF-YB (CBF-A or HAP3), NF-YA (CBF-B or HAP2) and NF-YC (CBF-C or HAP5) (Nardini et al., 2013; Wang et al., 2018b). The NF-Y TF family has been comprehensively studied in animal systems, and it was found that each subunit is encoded by a single gene in yeast and mammals (Mantovani., 1999). NF-Y transcription

719 factors interact with other factors in the regulatory network to induce or inhibit the expression of 
720 downstream target genes (Benatti et al., 2008). Unlike mammals and yeast, plants have many 721 NF-Y subunit genes (Wang et al., 2018b). For example, in Arabidopsis 13 genes encoding NF722 YB, 10 genes encoding NF-YA and 13 genes encoding NF-YC have been reported (Siefers et al., 723 2009). Additionally, individual NF-Y subunits have been shown to play vital roles in plant 724 abiotic stress tolerance (Sato et al., 2014; Ma et al., 2015).

725

726

727

728

729

730

731

732

733

734

735

736

737

738

739

740

741

742

743

744

745

746

747

748

749

750

751

752

753

754

755

756

757

758

759

760

761

762

Even though maize has numerous NF-Y subunits, very few studies have been done to investigate the roles these subunits play in response to abiotic stress (Wang et al., 2018b). Nelson et. (2007) demonstrated that transgenic maize with elevated levels of $Z m N F-Y B 2$ showed improved tolerance to drought stress based on responses from various stress-related parameters which included stomatal conductance, chlorophyll content, reduced wilting and leaf temperature (Table. 2). Recently, overexpression of a NF-YB transcription factor complex member designated as $\mathrm{ZmNF}-Y B 16$ resulted in improved drought and dehydration resistance in transgenic inbred maize line B104 during reproductive and vegetative stages (Wang et al., 2018b) (Table 1). Analysis of gene expression in the photosynthesis system between the WT and transgenic plants revealed that several genes were up-regulated in the transgenic plants when compared to the WT plants. Examples of genes up-regulated included GRMZM2G117572 (encoding the photosystem II PsbZ protein), GRMZM2G414660 (encoding the photosystem II cytochrome b599 subunit) and GRMZM5G831399 (encoding the photosystem II PsbH protein) among others.

Analysis of the co-expression between miR169, miRNA family and ZmNF-YA TFs in transgenic Nicotiana bethamiana revealed that mutations in deletion sites terminate the regulation of zma-miR169 (Luan et al., 2014). The expression levels of zma-miR169l, zma$m i R 169 i$, and zma-miR169a were all inversely correlated with ZmNF-YA11, ZmNF-YA6, and $Z m N F-Y A 7$ over the short term. However, over the long term, the expression levels of all the NFYA genes and miR169s decreased, revealing that ZmNF-YA11, ZmNF-YA6, and ZmNF-YA7 could not have been regulated by zma-miR169 in response to PEG stress after 15 days. Majority of the zma-miR169s were up-regulated by external ABA and down-regulated by drought stress but showed an early increase in expression and later a decline in response to salinity stress. Recently, Su et al. (2018) identified a NF-Y TF designated as ZmNF-YA3. Genome-wide analysis revealed that $Z m N F-Y A 3$ was linked to more than 6000 sites in the maize genome, 2259 of which are linked with genic sequences. Moreover, it was shown that ZmNF-YA3 could significantly improve high temperature and drought tolerance in maize by binding to the promoter region of three downstream genes (ZmMYC4, ZmbHLH92, and ZmFAMA).

In conclusion, all of the insights obtained above suggest NF-Y TFs play an important role in abiotic stress tolerance in maize by regulating several vital downstream genes involved in important aspects of abiotic stress responses, and plant growth and development, for instance, photosynthesis and ER stress response. Therefore, NF-Y TF genes could be engineered in maize and other crops in order to improve their abiotic stress tolerance, leading to improved production.

\section{Engineering of TFs}

The recent discovery of TFs as potential tools in the manipulation and engineering of quantitative traits such as drought and salinity has ignited the development of novel technologies based on TFs and benefiting not only gene discovery but also crop improvement. Engineering of $\mathrm{TF}$ activity has been a major target in these efforts, a direction that offers future promises in

PeerJ reviewing PDF | (2019:02:35201:1:2:REVIEW 9 May 2019) 
763

764

765

766

767

768

769

770

771

772

773

774

775

776

777

778

779

780

781

782

783

784

785

786

787

788

789

790

791

792

793

794

795

796

797

798

799

800

801

802

803

804

modulating metabolic pathways. For example, over-expression of DREB2 resulted in no stress tolerance improvement because proteins are composed of domains that limit the induction of their target genes downstream (Liu et al., 1998). Sakuma et al. (2006) obtained drought-tolerant plants by removing this repressor function through the engineering of point mutations. An undesirable effect of overexpressing stress-related TFs is that sometimes it negatively affects the growth and development of a plant leading to stunted growth or toxicity (Hussain and Amjad, 2011). Elsewhere, over-expression of $Z m D R E B 2 A$ under a stress-activated promoter in the transgenic plants led to significant improvement in drought tolerance (Qin et al., 2007).

Transcriptional down regulators that repress gene expression in response to various abiotic stresses are also important tools in manipulating drought tolerance. For example, over-expression of a yeast transcription repressor CaZPF1 in Arabidopsis led to drought tolerance in transgenic plants (Kim et al., 2004). In the model plant Arabidopsis, systematic analysis of TF families resulted in the discovery of target genes that have the potential to enhance abiotic stress tolerance in major crops (Reichmann et al., 2000). A good example is the discovery of AtNF-YBI gene that belongs to the Nuclear factor Y TF family (Nelson et al., 2007). The orthologue of (AtNF-YB1) gene in maize, $(Z m N F-Y B 2)$ when over-expressed in transgenic maize, resulted in droughttolerant crops (Table. 2). These findings emphasized the significance of TFs, especially when used in the engineering of plants.

The abiotic stress response networks in plants are very complex due to the large number of gene families involved and the complicated associations between the cis-acting elements and the TFs. In addition, a single TF may regulate a large number of target genes with similar cis-elements whereas TFs from different families may regulate a single target gene with different types of cisacting elements (Hussain and Amjad, 2011). Therefore, abiotic stresses regulating TFs not only function independently but also co-regulate abiotic stress responses between each other (Wang et al., 2016b) (Fig. 2). As mentioned throughout this review, genetic engineering of TF genes will be much more significant than manipulating a single functional gene. Thereafter, validation of the identified genes should be performed in model crops as well as the main crops by utilizing a stress-inducible promoter to reduce the detrimental effects brought about because of overexpression of certain TFs (Lan et al., 2017). Moving forward, all of these advances will help elucidate the detailed regulatory channels taking part in multiple abiotic stress responses in plants, leading to the acquisition of target TF genes for enhanced breeding of abiotic stresstolerant plants with improved desirable qualities and yields.

\section{Current and post genomics approaches}

Abiotic stresses represent a combination of various distinct traits consisting of a quantitative pattern of inheritance. Therefore, in order to efficiently understand the plants response to the different abiotic stresses at the molecular level, a deeper understanding of the systems involved in transcription regulation is required. Trait mapping, functional characterization, genomic selection, rapid RNA and DNA high-throughput SNP genotyping tools, sequencing technologies, and other platforms are currently used to analyze the genetic mechanisms of different abiotic stresses including drought, salinity, and cold in an effort to speed up the breeding process in maize (Nepolean et al., 2018).

Peer] reviewing PDF | (2019:02:35201:1:2:REVIEW 9 May 2019) 
805 Genome editing techniques are the most recent technologies applied in gene function analyses 806 and manipulations. RNA interference (RNAi) is a rapid and inexpensive technique utilized to 807 analyze gene function in targeted gene knockdown analyses (Rabara et al., 2014). However, a 808 disadvantage of this technique is that the inhibition of gene function is not complete and this 809 could lead to unintended off-target effects leading to misinterpretation of results (Gaj et al., 810 2013). Of the targeted genome editing approaches currently available, clustered regulatory 811 interspaced short palindromic repeats 'CRISPR' is the most effective system used in editing 812 plant genomes (Cong et al., 2013). CRISPR artificial transcription factors (CRISPR-ATFs) are 813 gaining popularity as an effective system for regulating in vivo plant gene expression (Lowder et al., 2018). For instance, two novel systems (CRISPR-Act2.0 and mTALE-Act) were developed that could be used to study gene regulatory networks and the control mechanisms involved in plants (Lowder et al., 2018).

The other systems are transcription activator-like effectors nucleases (TALENS) (Boch et al., 2009) and Zinc-finger nuclease (ZFNs) (Kim et al., 1996). Another approach with huge potentials in functional genomics in plants is targeting-induced local lesions in genomes (TILLING). For example, a TILLING approach known as ecotilling, which was used to identify variations in natural populations, was successfully used to identify TFs in rice associated with drought tolerance (Yu et al., 2012). These techniques are vital in the selection of better quality genotypes and target genes in the abiotic stress tolerance research in maize.

Another approach currently being explored is the use of machine learning in the study of TFs gene regulatory networks. Predictions of TF binding sites (TFBSs) and their corresponding transcription factor target genes (TFTGs) using machine learning approaches has made substantial contributions to the study of gene regulatory networks (Cui et al., 2014). Understanding the interplay between TFs, TFBSs and TFTGs is vital in understanding the mechanisms involved in the gene regulatory processes taking place during biotic and abiotic stress responses in plants. Various computational algorithms are available in form of software packages. Additionally, expansive use of these software packages has revealed that even though some techniques were developed for one species, the same techniques can be used to analyze the dataset from other species (Cui et al., 2014). For example, a combination of Context Likelihood of Relatedness algorithm analyzed on Escherichia coli (Faith et al., 2007), Double Two-way ttests algorithms analyzed on Escherichia coli and Learning Module Networks algorithm tested on yeast (Joshi et al., 2009) was used to identify the presence of oxidative stress regulatory transcription factors in Arabidopsis (Vermeirssen et al., 2014). Moreover, The Algorithm for the Reconstruction of Gene Regulatory Networks (ARACNE) (Margolin et al., 2006) was established to deduce transcriptional regulations in human immune B cells, but was later used to deduce transcriptional interactions regulating root physiological and developmental processes in Arabidopsis (Chavez et al., 2014).

842 Gene regulatory networks (GRNs) provide insights into the relationships between TFs and their corresponding target genes (Koryachko et al., 2015). For instance, network component analysis (NCA), a computational method developed for analysis of TF-gene interactions in microbial TFGRNs, was employed to quantitatively analyze TF-GRNs critical in floral development in Arabidopsis (Misra and Sriram, 2013). The results showed that the NCA model adequately accounted for the total gene expression analysis in a TF-GRN of seven TFs (AG, HY5, between different TF- gene pairs, such as, $L F Y$ and $M Y B 17, A G$ and $C R C, A P 2$ and $R D 20$, 
850

851

852

853

854

855

856

857

858

859

860

861

862

863

864

865

866

867

868

869

870

871

872

873

874

875

876

877

878

879

880

881

882

883

884

885

886

887

888

889

890

891

892

893

894

$A G L 15$ and RAV2 and finally HY5 and HLH1. In maize, a machine learning algorithm GENIE3 was used together with numerous RNA-Seq expression data to establish a four tissue (root, SAM, seed, and leaf) specific GRNs (Huang et al., 2017). The results showed that even though many TFs were expressed in multiple tissues, a multi-level examination predicted regulatory roles for many TFs. Additionally, 76.6\% (30,028/39479) of the genes were found to be expressed in all the maize tissues. Out of the total of 2587 TFs annotated by GRASSIUS in maize (Chen et al., 2013), 54.46\% were expressed in all the four tissues while $86.63 \%$ of the total TFs were expressed in at least one of the four tissues.

Understanding the mechanisms of gene regulatory networks (GRNs) is vital in gaining insights on how TFs control gene expression in response to various abiotic stresses. Wet lab experiments are technically demanding, time-consuming and financially demanding (Penfold and Wild, 2011). Many machine-learning approaches have been proposed with an aim of reducing costs and time spent in the prediction of GRNs. For instance, recent development of a publicly accessible maize TF ORF collection (TFome) consisting of 2034 clones that correspond to 2017 unique maize TFs and co-regulators (CoREGs), has vastly contributed to the better understanding of GRNs (Burdo et al., 2014). The TFome was generated from a set of full cDNAs (FL-cDNA) obtained from the Arizona Genomics Institute (AGI). The synthesis information, generated sequences, and request links for the maize TFome information are publicly available through GRASSIUS (http://grassius.org/tfomecollection.html). In conclusion, adaptation of available crop databases such as Gramene (Tello-Ruiz et al., 2018), and GRASSIUS for maize in machine learning approaches, as well as developing and adopting new databases for example the Wheat Information System (WheatIS) (Hu et al., 2018) will help in the storage of data at the same time making it more accessible to scientists.

Traditional breeding techniques for selecting desirable traits depend on the observed phenotypic traits which can be misleading sometimes during selection, and this has led to low success in such strategies. Genomic selection is an accurate and efficient approach when it comes to the prediction of genotypic performance in crops. In maize, utilization of genomic techniques in the manipulation and analyses of TFs has been reported in a few studies. For instance, Mittal et al. (2017) utilized genomic selection techniques on 240 subtropical maize lines during exposure to drought by selecting 29,619 SNPs. The study found that 77 out of 1053 SNPs were linked with 10 drought associated TFs located inside a $150 \mathrm{~kb}$ area. For example, MYB $(149 \mathrm{~Kb})$, WRKY $(125 \mathrm{~Kb})$, NAC $(149 \mathrm{~Kb})$, bZIP $(92 \mathrm{~Kb})$, and AP-ERF $(148 \mathrm{~Kb})$ among others. Similarly, transcriptome analysis of two maize inbred lines using RNA-Seq showed that a total of 2558 and 555 genes responded to drought in both the sensitive and the tolerant lines respectively (Zhang et al., 2017a). TFs were found to be enriched in the genotype-specific responsive genes, and the genotypic differentially expressed genes. It was postulated that the differential expression of 22 $\mathrm{TF}$ genes and the genotype-specific response of $20 \mathrm{TFs}$ in the tolerant line might play an important role in drought tolerance enhancement in maize. Zhang et al. (2017b) utilized RNASeq platform to analyze the expression of TFs in response to lead stress in a maize 178 leadtolerant line. In this study, a total of 464 genes were expressed, among which 262 differentially expressed TFs (DETs) which responded to $\mathrm{Pb}$ treatment were identified. More recently, (Zhao et al., 2018) mapped several abiotic stress responsive TFs to QTLs. The results showed that MYB78 and $h s p 70$ were mapped to mQTL1-5. On chromosome 6, pep 7 and mlip 15 were both mapped on mQTL6-1. Kusano et al. (1995) demonstrated that mlip15 was a low-temperature activated gene that encodes a bZIP protein made up of 135 amino acid. Elsewhere, global transcriptome

Peer) reviewing PDF | (2019:02:35201:1:2:REVIEW 9 May 2019) 
895

896

897

898

899

900

901

902

903

904

905

906

907

908

909

910

911

912

913

914

915

916

917

918

919

920

921

922

923

924

925

926

927

928

929

930

931

932

933

934

935

936

937

938

profiling using RNA-seq on B73 maize seedlings exposed to heat, drought, cold stress, and salinity revealed 5,330 differentially expressed genes (DEGs) (Li et al 2017). Functional annotations of these DEGs suggested that the pathways involving TFs, hormone metabolism and signaling among others controlled the stress responses. Among the 5,330 DEGs obtained, 167 genes were common to the four abiotic stresses; these included two down-regulated TFs (one MYB related and one b-ZIP) and 10 up-regulated TFs (one ARF, five ERFs, one MYB, one HDZIP, and two NAC). This study significantly contributes to a deeper understanding of molecular mechanisms involved in maize leaf responses to different abiotic stresses and could eventually contribute to the development of maize cultivars that are tolerant to various abiotic stresses.

Approaches involving genome-editing techniques create possibilities allowing for gene knockouts, point mutations, epigenetic changes, and the activation or repression of genes (Kamburova et al., 2017). Svitashev et al. (2016) reported the use of biolistic delivery of Cas9gRNA ribonucleoproteins in maize cells, and this approach resulted in plants with both edited and mutated alleles. Recently, (Cox et al., 2017) reported the use of single-effector programmable RNA guided RNases Cas13. This marks a major leap in plant transformation opening new opportunities in accelerated breeding in other main crops such as wheat, soybeans, sorghum, and rice. By using the RNA editing tools, the DNA structure is left intact but the function of the TF genes is manipulated. Utilization of genome editing techniques is still in its infancy and it is yet to be fully explored for abiotic stress tolerance in maize.

\section{Future outlook}

Recent advances in genomics, molecular biology, metabolomics and proteomics have yielded fresh insights into the plant gene regulatory network, composed mainly of regulatory elements (trans-elements and cis-elements), inducible genes (developmental and environmental cues), varying signal factors and complementary biochemical pathways (Tang et al., 2003; Wang et al., 2003; Zhu., 2002). Sequencing of the whole maize genome has provided a basis for the functional characterization and identification of genetic networks and genes for maize improvement (Schnable et al., 2009). Moreover, recent availability of transcriptome profiling technologies, including genome sequencing and DNA microarrays, has opened new doors for understanding the patterns of transcription in the area of plant growth and development (Sekhon et al., 2011).

Understanding the genetic architecture of the molecular networks involved in maize, by utilizing current "OMICS" technologies is urgently needed to unravel the drought, heat and salt tolerance mechanisms in maize. Numerous genetic studies have shown that abiotic stress tolerance traits are usually polygenic making the selection of such traits extremely difficult (Loredana et al., 2011). With the recent whole-genome sequencing of the B73 maize line, it's now feasible to identify most maize TFs and systematically estimate their contribution to abiotic stress tolerance. Maize has an increased level of genetic disequilibrium linkage (LD) and genetic diversity making it an ideal plant species since the LD and genetic diversity have been predicted to be within a number of kilobases (kbs) in maize landraces (Tenaillon et al., 2003). This characteristic makes genome-wide association studies (GWAS) at the gene level more accurate when compared to self-pollinated plant species as long as genome-wide and high-density DNA markers are present (Yan et al., 2011; Li et al., 2012). For example, using a Bayesian-based genome-wide association method in which RNA-seq-based systems of transcript buildup were

Peer] reviewing PDF | (2019:02:35201:1:2:REVIEW 9 May 2019) 
939

940

941

942

943

944

945

946

947

948

949

950

951

952

953

954

955

956

957

958

959

960

961

962

963

964

965

966

967

968

969

970

971

972

973

974

975

976

977

978

979

980

981

982 utilized as explanatory variables (eRD-GWAS), genes linked to 13 traits were discovered from a group of 369 inbred maize lines (Lin et al., 2017). Additionally, TFs were found to be considerably enriched among the trait-associated genes discovered with eRD-GWAS. Similarly, genome-wide analyses carried out on the maize B73 inbred line to identify all the Hsf genes identified 25 non-redundant Hsf genes designated as ZmHsfs (Lin et al., 2011). In soybean, an all-inclusive phylogenetic study revealed 58 dehydration responsive genes from the GmNAC TF family (Le et al., 2011). RNA sequencing performed on 14-day old maize seedlings of inbred lines Mo17, B73, PH207, B37 and Oh43 under heat, cold and control treatments, revealed a large number of genes that responded differentially between parental inbred lines (Waters et al., 2017). Moreover, 20 of the 57 annotated TF families in maize were enriched for elevated genes in heat and/or cold stress in at least three of the five inbred genotypes. Finally, TF families with TFs that were enriched for up-regulated genes in response to heat stress included MYB and HSF TF families, while $18 \mathrm{TF}$ families with TFs enriched for up-regulated genes in response to cold stress included APETALA2/ (AP2/EREB).

A new approach currently gaining rapid popularity is the field of phenomics. By utilizing highthroughput phenotyping, various physiological parameters such as biomass, internode length, leaf area, chlorophyll content, plant width and height, and growth rate can be accurately determined in real time and noninvasively (Rabara et al., 2014). Large amounts of quality phenomics data can be generated for many transgenic plants. Currently, field phenotyping systems are being developed with the capacity to determine whether the engineering of TFs in plants can improve abiotic stress tolerance (Rabara et al., 2014). For instance, Awlia et al. (2016) demonstrated that the phenotyping of polygenic traits in one experimental study could provide new insights into the mechanisms of plant responses to different abiotic stresses. The establishment of new phenomics technologies will further strengthen the use of forward genetics in the identification of novel TF genes regulating plant responses to different abiotic stresses.

Since TFs tend to regulate multiple pathways as opposed to a majority of the structural genes, they offer a powerful and unique system for use in the control of complex regulatory networks in plants. Over-expression of genes regulating the transcription of several down-stream abiotic/drought stress regulatory genes is a much better approach in the engineering of drought tolerant/resistant plants as opposed to the development of specific functional genes (Bartels and Hussain, 2008). Development of transgenic plants with enhanced abiotic stress tolerance by regulating TFs has become an important aspect of abiotic stress tolerance. Members of the WRKY, MYB, AREB, and bZIP, TF families have recently been utilized in the regulation of abiotic stress responses in major crops (Singh et al., 2002). Many of the members belonging to these TF families have been identified and characterized in Arabidopsis, whose genome has been analyzed using microarray analysis, thus leading to the discovery of potential genes (Shinozaki., 2003; Bray., 2004; Denby and Gehring, 2005). Thus TF families offer important targets for use in gene manipulation and regulation which could be vital in understanding responses involved in abiotic stress tolerance. An increasing trend has seen the engineering of TFs involved in stresssignaling networks using biotechnology tools to generate transgenic stress tolerant plants. (Abe et al., 2003; Sakuma et al., 2006). 


\section{Conclusion}

985

986

987

988

989

990

991

992

993

994

995

996

997

998

999

1000

1001

1002

1003

1004

1005

1006

1007

1008

1009

1010

1011

1012

1013

1014

1015

1016

1017

1018

1019

1020

1021

1022

1023

1024

The population in our planet is projected to rise to 9 billion by the year 2050 (Hussain., 2006), together with the rapid changes in climate there is an urgent need to speed up the productivity of major crops. Understanding molecular mechanisms and mining stress-responsive genes that control plant responses to different abiotic stresses is a major prerequisite in the development of stress-resistant and high yielding crop varieties (Khan et al., 2018). To safeguard the global food production, crops (like maize) that are well adapted to adverse environmental conditions should be established (Vinocur and Altman, 2005).

Maize is highly affected by abiotic stresses especially drought throughout its growth cycle, with the most damage being seen during the developmental stage and prior to flowering (Claassen and Shaw, 1970). TF mediated research in plants has recently shown progressive improvement since most of the TF encoding genes are early stress-responsive genes which control the expression of various downstream target genes (Lan et al., 2017). This has in turn led to a deeper understanding of the involvement and functions of TFs in plant responses to different abiotic stresses (Bartels and Sunkar, 2005).

This review emphasizes on the main TF families and their potential in abiotic stress tolerance in maize. The majority of the $\mathrm{TF}$ genes in the literature are reported to play major roles in multiple abiotic stress tolerances. Among the target genes for engineering, the utilization of TFs has been recommended as they have potential to revolutionize biotechnology upon which novel crops with improved tolerance to abiotic stresses could be successfully generated. There is absence of literature available on abiotic stress responsive TFs with agronomic traits that have been utilized in maize in field conditions. Although Monsanto has developed, a biotechnology-derived inbred maize line that expresses HB17 (ATHB17), a TF from Arabidopsis (Park et al., 2013; Hymus et al., 2013). Expression of ATHB17 in the inbred line is linked with increased ear biomass at the silking stage compared to the near-isogenic controls (Rice et al., 2014). Increased ear biomass at the early stage of plant development is associated with increased sink size and greater grain yield from hybrid maize (Borras and Wetgate, 2006; Lee and Tollenaar, 2007).

TFs are excellent candidates for the development of transgenic crops because of their roles in plant growth and development. Incorporation of abiotic stress response pathways in the vital reproductive and vegetative development stages in crops is an efficient strategy to improve productivity in field conditions (Nelson et al., 2007). TFs can be used to simulate a variety of developmental and biochemical networks that take part in the regulation of abiotic stresses, thus increasing the performance of crops in response to multiple plant abiotic stresses. Joshi et al. (2016) noted that over-expression of several TF genes significantly enhanced abiotic stress tolerance but at the same time caused a number of negative effects including lower yields, late flowering and dwarfing in transgenic plants. This should be considered in future studies to maximize the effectiveness of TF engineering in responses to different abiotic stresses.

Moving forward, identification and characterization of multiple stress regulatory genes should be given more focus not only in maize but also in other major crops to target the most effective genes that can be universally used to develop abiotic stress tolerant crop varieties. Machine learning algorithms can be integrated with transcriptome data and high-throughput phenotyping 
1025

1026

1027

1028

1029

1030

1031

1032

1033

1034

1035

1036

1037

1038

1039

1040

1041

1042

1043

1044

1045

1046

1047

1048

1049

1050

1051

1052

1053

1054

1055

1056

1057

1058

1059

1060

1061

1062

1063

data to further increase the automation of the gene discovery processes such as genome annotation and gene regulatory networks (GRNs) predictions.

Genetic engineering of multiple stress regulatory TF genes is a strong candidate for the enhancement of stress tolerance in plants when compared to focusing on a single individual gene. Nevertheless, recent advances in maize breeding, genomics and functional analysis of genes combined with high-throughput sequencing technologies have significantly increased the chances of achieving multiple stress tolerances. The identification of commercial transgenic plants with enhanced crop performance under stress conditions is a tedious, expensive and lengthy process. However, the successful genetic engineering of maize for improved abiotic stress tolerance using TFs as reviewed herein confirms this approach is feasible.

Since maize is a major crop in many countries, there is need for more collaboration in both applied and theoretical genomics in order to improve the production of maize. The rapid advancements in TFs genome analysis currently being witnessed are mostly on temperate maize varieties. It is hoped that these technologies can be transferred to subtropical and tropical maize varieties that serve as essential food security crop in developing countries.

\section{Acknowledgment}

The authors would like to sincerely thank the Center for Agricultural Resource Research, Institute of Genetics and Developmental biology (CAS) for availing the facilities.

\section{References}

Abe H., Urao T., Ito T., Seki M., Shinozaki K., Yamaguchi-Shinozaki K. (2003) Arabidopsis AtMYC2 (bHLH) and AtMYB2 (MYB) function as transcriptional activators in abscisic acid signaling. Plant Cell 5:63-78

Abe H., Yamaguchi-Shinozaki K., Urao T., Iwasaki T., Hosokawa D., Shinozaki K. (1997) Role of Arabidopsis MYC and MYB homologs in drought- and abscisic acid-regulated gene expression. The Plant Cell 9: 1859-1868.

Agalou A, Purwantomo S, Overnäs E, Johannesson H, Zhu X, Estiati A, de Kam RJ, Engström P, Slamet-Loedin IH, Zhu Z, Wang M, Xiong L, Meijer AH, Ouwerkerk PB. (2008) A genome-wide survey of HD-Zip genes in rice and analysis of drought-responsive family members. Plant Mol. Biol.66: 87-103.

Ahuja I, de Vos RC, and Bones AM. (2010). Plant molecular stress responses face climate change. Trends Plant Sci 15, 664-674.

Allan A.C. \& Fluhr R. (2007). Ozone and Reactive Oxygen Species. Encyclopedia of Life Sciences, DOI: 10.1038/npg.els.0001299

Almoguera, C., Rojas, A., Díaz-Martín J., Prieto-Dapena, P., Carranco R. (2002) A seed-specific heat-shock transcription factor involved in developmental regulation during embryogenesis in sunflower. Journal of Biological Chemistry277, 43866-43872. doi:10.1074/jbc.M207330200 
1064

1065

1066

1067

1068

1069

1070

1071

1072

1073

1074

1075

1076

1077

1078

1079

1080

1081

1082

1083

1084

1085

1086

1087

1088

1089

1090

1091

1092

1093

1094

1095

1096

1097

1098

1099

1100

1101
Amajová O., Plíhal O., Al-Yousif M., Hirt H., Šamaj J. (2013). Improvement of stress tolerance in plants by genetic manipulation of mitogen-activated protein kinases. Biotechnol. Adv.31:118- 128. doi: 10.1016/j.biotechadv.2011.12.002.

Ariel, F.D., Manavella, P.A., Dezar, C.A. and Chan, R.L. (2007) The true story of the HD-Zip family. Trends Plant Sci.12: 419-426.

Ashburner M, Bonner JJ. (1979). The induction of gene activity in drosophila by heat shock. Cell 17: 241-54

Awlia, M., Nigro, A., Fajkus, J., Schmoeckel, S. M., Negrão, S., Santelia, D., Trtílek, M., Tester, M., Julkowska, M. M., ... Panzarová, K. (2016). High-Throughput Non-destructive Phenotyping of Traits that Contribute to Salinity Tolerance in Arabidopsis thaliana. Frontiers in plant science, 7,1414 . doi:10.3389/fpls.2016.01414

Banti, V., Mafessoni, F., Loreti, E., Alpi, A., \& Perata, P. (2010). The Heat-Inducible Transcription Factor HsfA2 Enhances Anoxia Tolerance in Arabidopsis. Plant Physiology, 152(3), 1471-1483. http://doi.org/10.1104/pp.109.149815

Bartoli C.G., Casalongué C.A., Simontacchi M., Marquez-Garcia B., Foyer C.H. (2013). Interactions between hormone and redox signaling pathways in the control of growth and cross- tolerance to stress. Environ. Exp. Bot.94:73-88. doi: 10.1016/j.envexpbot.2012.05.003.

Bartels D, Sunkar R (2005) Drought and salt tolerance in plants. Crit Rev Plant Sci 24:23-58

Benatti, P., Basile, V., Merico, D., Fantoni, L. I., Tagliafico, E., and Imbriano, C. (2008). Balance between NF-Y and p53 governs the pro- and anti-apoptotic transcriptional response. Nucleic Acids Res. 36, 1415-1428. doi: 10.1093/nar/ gkm1046

Bennetzen, J.L. and Hake, S. (2009) Handbook of Maize: Genetics and Genomics. New York: Springer.

Boch J, Scholze H, Schornack S, Landgraf A, Hahn S, Kay S, Lahaye T, Nickstadt A, Bonas U. (2009). Breaking the code of DNA binding specificity of TAL-Type III Effectors. Science 80, 1509-1512. doi: $\quad$ 10.1126/science.1178811

Borras, L., Slafer, G.A. and Otegui, M.E. (2004) Seed dry weight response to source-sink manipulations in wheat, maize and soybean: a quantitative reappraisal. Field Crops Res.86, 131-146.

Bray EA. (2004). Genes commonly regulated by water-deficit stress in Arabidopsis thaliana. J Exp Bot; 55:2331-2341.

Butt, H. I., Yang, Z., Chen, E., Zhao, G., Gong, Q., Yang, Z., ... Li, F. (2017). Functional Characterization of Cotton GaMYB62L, a Novel R2R3 TF in Transgenic Arabidopsis. PLoS ONE, 12(1), e0170578. http://doi.org/10.1371/journal.pone.0170578

Burdo, B., Gray, J., Goetting-minesky, M. P., Wittler, B., Hunt, M., Li, T., ... Grotewold, E. (2014). The Maize TFome development of a transcription factor open reading frame 
1102

1103

1104

1105

1106

1107

1108

1109

1110

1111

1112

1113

1114

1115

1116

1117

1118

1119

1120

1121

1122

1123

1124

1125

1126

1127

1128

1129

1130

1131

1132

1133

1134

1135

1136

1137

1138

1139

1140

collection for functional genomics, The Plant Journal (80) 356-366. https://doi.org/10.1111/tpj.12623

Cai, R., Dai, W., Zhang, C., Wang, Y., Wu, M., \& Zhao, Y. (2017). The maize WRKY transcription factor $Z m W R K Y 17$ negatively regulates salt stress tolerance in transgenic Arabidopsis plants. Planta. https://doi.org/10.1007/s00425-017-2766-9

Cai, R., Zhao, Y., Wang, Y., Lin, Y., \& Peng, X. (2014). Overexpression of a maize WRKY58 gene enhances drought and salt tolerance in transgenic rice. Springer: https://doi.org/10.1007/s11240-014-0556-7

Cao, L., Yu, Y., Ding, X., Zhu, D., Yang, F., Liu, B., Sun, X., Duan, X., Yin, K., Zhu, Y. (2017) The Glycine soja NAC transcription factor GsNAC019 mediates the regulation of plant alkaline tolerance and ABA sensitivity. Plant Mol. Biol. 95, 253-268. doi:10.1007/s11103-017-0643-3

Casaretto, J. A., El-Kereamy, A., Zeng, B., Stiegelmeyer, S. M., Chen, X., Bi, Y. M., \& Rothstein, S. J. (2016). Expression of OSMYB55 in maize activates stress-responsive genes and enhances heat and drought tolerance. BMC genomics, 17, 312. doi:10.1186/s12864-016-2659-5

Chang $\mathrm{W}$ and Yin D (2009) Overexpression of maize ZmDBP3 enhances tolerance to drought and cold stress in transgenic Arabidopsis plantsBiologia64/6: 1108-1114, Section Cellular and Molecular Biology DOI: 10.2478/s11756-009-0198-0

Chávez Montes, R. A., Coello, G., González-Aguilera, K. L., Marsch-Martínez, N., de Folter, S., \& Alvarez-Buylla, E. R. (2014). ARACNe-based inference, using curated microarray data, of Arabidopsis thaliana root transcriptional regulatory networks. BMC Plant Biology, 14, 97. http://doi.org/10.1186/1471-2229-14-97

Chaves M.M. \& Oliveira M.M. (2004). Mechanisms underlying plant resilience to water deficits: prospects for water-saving agriculture. Journal of Experimental Botany, 55 (407), 23652384

Chen, Y. H., Cao, Y. Y., Wang, L. J., Li, L. M., Yang, J., \& Zou, M. X. (2017) Identification of MYB transcription factor genes and their expression during abiotic stresses in maize, Biol Plant. 0006-3134, http://sci-hub.tw/10.1007/s10535-017-0756-1.

Chen, S., Huang, X., Yan, X., Liang, Y., Wang, Y., Li, X., ... Liu, G. (2013). Transcriptome Analysis in Sheepgrass (Leymus chinensis): A Dominant Perennial Grass of the Eurasian Steppe. PLoS ONE, 8(7), e67974. http://doi.org/10.1371/journal.pone.0067974

Chen H, Lai Z, Shi J, Xiao Y, Chen Z, Xu X (2010) Roles of ArabidopsisWRKY18, WRKY40 and WRKY60 transcription factors in plant responses to abscisic acid and abiotic stress. BMC Plant Biol 10:281

Chew, W., Hrmova, M., \& Lopato, S. (2013). Role of homeodomain leucine zipper (HD-Zip) iv transcription factors in plant development and plant protection from deleterious environmental factors. International Journal of Molecular Sciences, 14(4), 8122-8147. https://doi.org/10.3390/ijms14048122 
1141

1142

1143

1144

1145

1146

1147

1148

1149

1150

1151

1152

1153

1154

1155

1156

1157

1158

1159

1160

1161

1162

1163

1164

1165

1166

1167

1168

1169

1170

1171

1172

1173

1174

1175

1176

1177

1178

Christianson, J. A., Dennis, E. S., Llewellyn, D. J., and Wilson, I. W. (2010). ATAF NAC transcription factors: regulators of plant stress signaling. Plant Signal. Behav. 5, 428-432. doi: $10.4161 /$ psb.5.4.10847

Claassen MM, Shaw RH (1970) Agron J62:652-655

Cong L, Ran FA, Cox D, Lin S, Barretto R, Habib N, Hsu PD, Wu X, Jiang W, Marraffini LA, Zhang F. (2013). Multiplex genome engineering using CRISPR/Cas systems. HHS Public Access, 339(6121), 819-823. https://doi.org/10.1126/science.1231143

Cox, D. B. T., Gootenberg, J. S., Abudayyeh, O. O., Franklin, B., Kellner, M. J., Joung, J., \& Zhang, F. (2017). RNA editing with CRISPR-Cas13. Science, 358(6366), 1019-1027. doi:10.1126/science.aaq0180

Cui, S., Youn, E., Lee, J., \& Maas, S. J. (2014). An Improved Systematic Approach to Predicting Transcription Factor Target Genes Using Support Vector Machine. PLoS ONE, 9(4), e94519. http://doi.org/10.1371/journal.pone.0094519

Cutler SR, Rodriguez PL, Finkelstein RR, Abrams SR (2010) Abscisic acid: Emergence of a core signaling network. Annual Reviews in Plant Biology 61: 651-679.

Dash, S., Van Hemert, J., Hong, L., Wise, R.P. and Dickerson, J.A. (2012) PLEXdb: gene expression resources for plants and plant pathogens, Nucleic Acids Res., 40, D1194-201.

Denby K, Gehring C. (2005). Engineering drought and salinity tolerance in plants: lessons from genome-wide expression profiling in Arabidopsis. Trends Plant Sci; 23:547-552.

Dixit S, Biswal AK, Min A, Henry A, Oane RH, Raorane ML, Longkumer T, Pabuayon IM, Mutte SK, Vardarajan AR, Miro B, Govindan G, Albano-Enriquez B, Pueffeld M, Sreenivasulu N, Slamet-Loedin I, Sundarvelpandian K, Tsai Y-C, Raghuvanshi S, Hsing Y-IC, Kumar A, Kohli A. (2015). Action of multiple intra-QTL genes concerted around a co-localized transcription factor underpins a large effect QTL. Sci Rep 5:15183

Dombrowski J.E. (2003). Salt Stress Activation of Wound-Related Genes in Tomato Plants. Plant Physiology, 132, 2098-2107

Dong, W., Song, Y., Zhao, Z., Qiu, N.W., Liu, X., Guo, W. (2017). The Medicago truncatula R2R3-MYB transcription factor gene MtMYBS1 enhances salinity tolerance when constitutively expressed in Arabidopsis thaliana. Biochem. Biophys. Res. Commun. 490, 225-230. doi: 10.1016/j.bbrc.2017.06.025

Dong, Y., Wang, C., Han, X., Tang, S., Liu, S., Xia, X., Yin, W. (2014). A novel bHLH transcription factor PebHLH35 from Populus euphratica confers drought tolerance through regulating stomatal development, photosynthesis and growth in Arabidopsis. Biochem Biophys Res Commun, 450(1), 453-458. doi:10.1016/j.bbrc.2014.05.139

Dou, T., Hu, C., Sun, X., Shao, X., Wu, J., Ding, L., Jie, g., Wei, H.,Manosh, B., Qiao, Y., Yi, G. (2015). MpMYBS3 as a crucial transcription factor of cold signaling confers the cold tolerance of banana. Plant Cell, Tissue and Organ Culture (PCTOC), 125(1), 93-106. doi:10.1007/s1 1240-015-0932-y

PeerJ reviewing PDF | (2019:02:35201:1:2:REVIEW 9 May 2019) 
1179

1180

1181

1182

1183

1184

1185

1186

1187

1188

1189

1190

1191

1192

1193

1194

1195

1196

1197

1198

1199

1200

1201

1202

1203

1204

1205

1206

1207

1208

1209

1210

1211

1212

1213

1214

1215

1216

1217

Du, H. A. I., Wang, Y. O. N. G. I. N., Xie, Y. I., Liang, Z. H. E., Jiang, S. A. N. I. E., Zhang, S. H. H., \& Huang, Y. U. I. (2013). Genome-Wide Identification and Evolutionary and Expression Analyses of MYB-Related Genes in Land Plants, 1(May), 437-448.

Echevarría-Zomeño, S., Fernández-Calvino, L., Castro-Sanz, A. B., López, J. A., Vázquez, J., \& Castellano, M. M. (2016). Dissecting the proteome dynamics of the early heat stress response leading to plant survival or death in Arabidopsis. Plant, Cell \& Environment, 39, 1264-1278. https://doi.org/10.1111/pce.12664

El-Kereamy A., Bi Y.-M., Ranathunge K., Beatty P. H., Good A. G., Rothstein S. J. (2012). The rice R2R3-MYB transcription factor OsMYB55 is involved in the tolerance to high temperature and modulates amino acid metabolism. PLoS One 7:e52030. 10.1371/journal.pone.0052030

Faith, J. J., Hayete, B., Thaden, J. T., Mogno, I., Wierzbowski, J., Cottarel, G., ... Gardner, T. S. (2007). Large-Scale Mapping and Validation of Escherichia coli Transcriptional Regulation from a Compendium of Expression Profiles, PLoS Biol. 5 (1). https://doi.org/10.1371/journal.pbio.0050008

Fornalé, S., Shi, X., Chai, C., Encina, A., Irar, S., Capellades, M., Fuguet, E., Torres, J.L., Rovira, P., Puigdomenech, p., Rigau, J., Grotewold, E., Gray, J., Caparrós-Ruiz, D. (2010). ZmMYB31 directly represses maize lignin genes and redirects the phenylpropanoid metabolic flux. Plant Journal, 64(4), 633-644. https://doi.org/10.1111/j.1365-313X.2010.04363.x

FrancoZorrilla,J.M.,LópezVidriero,I.,Carrasco,J.L.,Godoy,M.,Vera,P,and,Solano,R.(2014). DNA -binding specificities of plant transcription factors and their potential to define target genes. Proc. Natl.Acad.Sci.U.S.A. 111, 2367-2372. doi:10.1073/pnas.1316278111

Gahlaut, V., Jaiswal, V., Kumar, A., \& Gupta, P. K. (2016). Transcription factors involved in drought tolerance and their possible role in developing drought tolerant cultivars with emphasis on wheat (Triticum aestivum L.). Theoretical and Applied Genetics. https://doi.org/10.1007/s00122-016-2794-z

Gaj T, Gersbach CA, and Barbas CF, 3rd. (2013). ZFN, TALEN, and CRISPR/Cas-based methods for genome engineering. Trends Biotechnol 31, 397-405.

Giraudat J, Parcy F, Bertauche N, Gosti F, Leung J, Morris P, Bouvier-Durand M, Vartanian N (1994) Current advances in abscisic acid action and signaling. Plant Molecular Biology 26: $1557-1577$.

Gong, F., Yang, L., Tai, F., Hu, X., \& Wang, W. (2014). "Omics" of maize stress response for sustainable food production: opportunities and challenges. Omics : a journal of integrative biology, 18(12), 714-32.

Gupta, K., Jha, B., Agarwal, P.K. (2014). A dehydration-responsive element binding (DREB) transcription factor from the succulent halophyte Salicornia brachiata enhances abiotic stress tolerance in transgenic tobacco. Mar. Biotechnol. 16, 657-673. doi: http://scihub.tw/10.1007/s10126-014-9582-z

Peer) reviewing PDF | (2019:02:35201:1:2:REVIEW 9 May 2019) 
$1218 \mathrm{Hu}, \mathrm{H}$. , Scheben, A., \& Edwards, D. (2018). Advances in Integrating Genomics and

1219

1220

1221

1222

1223

1224

1225

1226

1227

1228

1229

1230

1231

1232

1233

1234

1235

1236

1237

1238

1239

1240

1241

1242

1243

1244

1245

1246

1247

1248

1249

1250

1251

1252

1253

1254

1255

1256

Bioinformatics in the Plant Breeding Pipeline. Agriculture, 8(6), 75. doi:10.3390/agriculture 8060075

Hu H, You J, Fang Y, Zhu X, Qi Z, Xiong L (2008) Characterization of transcription factor gene $S N A C 2$ conferring cold and salt tolerance in rice. Plant Molecular Biology 67: 169-18

Hu, H., Dai, M., Yao, J., Xiao, B., Li, X., Zhang, Q., \& Xiong, L. (2006). Overexpressing a NAM, ATAF, and CUC (NAC) transcription factor enhances drought resistance and salt tolerance in rice. Proceedings of the National Academy of Sciences of the United States of America, 103(35), 12987-12992. http://doi.org/10.1073/pnas.0604882103

Huang, J., Zheng, J., Yuan, H., \& McGinnis, K. (2018). Distinct tissue-specific transcriptional regulation revealed by gene regulatory networks in maize. BMC Plant Biology, 18, 111. http://doi.org/10.1186/s12870-018-1329-y

Hübel A, SchöfflF (1994). Arabidopsis heat shock factor: isolation and characterization of the gene and the recombinant protein. Plant Molecular Biology26, 353-362. doi:10.1007/BF00039545

Hussain SS, \& Amjad, M. (2011). Transcription Factors as Tools to Engineer Enhanced Drought Stress Tolerance in Plants. American Institute of Chemical Engineers Biotechnol. Prog.,27: 297-306, https://doi.org/10.1002/btpr.514

Hussain SS. (2006). Molecular breeding for abiotic stress tolerance: drought perspective. Proc Pak Acad Sci; 43:189-210.

Hymus GJ, Cai S, Kohl EA, Holtan HE, Marion CM, Tiwari S, Maszle DR, Lundgren MR, Hong MC, Channa N, Loida P, Thompson R, Taylor JP, Rice E, Repetti PP, Ratcliffe OJ, Reuber TL, Creelman RA. (2013) Application of HB17, an Arabidopsis class II homeodomain-leucine zipper transcription factor, to regulate chloroplast number and photosynthetic capacity.J. Exp. Bot.64, 4479-4490.

Jaglo-Ottosen KR, Gilmour SJ, Zarka DG, Schabenberger O, and Thomashow MF (1998) Arabidopsis $C B F 1$ overexpression induces $C O R$ genes and enhances freezing tolerance. Science 280:104-106

Jakoby M, Weisshaar B, Dröge-Laser W, Vicente-Carbajosa J, Tiedemann J, Kroj T, Parcy F (2002) bZIP transcription factors in Arabidopsis. Trends Plant Sci 7:106-111

Jia, Z., Lian, Y., Zhu, Y., He, J., Cao, Z., \& Wang, G. (2009). Cloning and characterization of a putative transcription factor induced by abiotic stress in Zea mays. African Journal of Biotechnology, 8(24), 6764-6771.

Jiang Y., Yang B., Harris N.S. \& Deyholos M.K. (2007). Comparative proteomic analysis of $\mathrm{NaCl}$ stress-responsive proteins in Arabidopsis roots. Journal of Experimental Botany, $58,3591-3607$

Jin, C., Li, K.-Q., Xu, X.-Y., Zhang, H.-P., Chen, H.-X., Chen, Y.-H., Zhang, S.-L. (2017). A Novel NAC Transcription Factor, PbeNAC1, of Pyrus betulifolia Confers Cold and Drought Tolerance via Interacting with PbeDREBs and Activating the Expression of 
1257

1258

1259

1260

1261

1262

1263

1264

1265

1266

1267

1268

1269

1270

1271

1272

1273

1274

1275

1276

1277

1278

1279

1280

1281

1282

1283

1284

1285

1286

1287

1288

1289

1290

1291

1292

1293

1294

Stress-Responsive Genes. Frontiers in Plant Science, 8, 1049. http://doi.org/10.3389/fpls.2017.01049

Jin J, Zhang H, Kong L, Gao G, Luo J (2014) Plant TFDB 3.0: a portal for the functional and evolutionary study of plant transcription factors. Nucl Acids Res 42:D1182-D1187

Jinhui Song, Qiaoyun Weng, Hailian Ma, Jincheng Yuan, Lingyun Wang \& Yinghui Liu (2016) Cloning and expression analysis of the Hsp70 gene ZmERD2 in Zea mays, Biotechnology \& Biotechnological Equipment, 30:2, 219-226, DOI: 10.1080/13102818.2015.1131625

Johannesson H, Wang Y, Hanson J, Engstrom P (2003) The Arabidopsis thaliana homeobox gene ATHB5 is a potential regulator of abscisic acid responsiveness in developing seedlings. Plant Mol Biol 51: 719-729

Joshi R, Wani SH, Singh B, Bohra A, Dar ZA, Lone AA, Pareek A and Singla-Pareek SL (2016) Transcription Factors and Plants Response to Drought Stress: Current Understanding and Future Directions. Front. Plant Sci. 7:1029. doi: 10.3389/fpls.2016.01029

Joshi, A., Smet, R. De, Marchal, K., Peer, Y. Van De, \& Michoel, T. (2009). Module networks revisited: computational assessment and prioritization of model predictions, Bioinformatics. 25(4), 490-496. https://doi.org/10.1093/bioinformatics/btn658

Kamburova, V. S., Nikitina, E. V., Shermatov, S. E., Buriev, Z. T., Kumpatla, S. P., Emani, C., \& Abdurakhmonov, I. Y. (2017). Genome Editing in Plants: An Overview of Tools and Applications. International Journal of Agronomy, 2017, 1-15. doi:10.1155/2017/7315351 Kasuga M, Liu Q, Miura S, Yamaguchi-Shinozaki K, Shinozaki K (1999) Improving

plant drought, salt, and freezing tolerance by gene transfer of a single stress-inducible transcription factor. Nat Biotechnol 17:287-291

Khan, S., Li, M., Wang, S., \& Yin, H. (2018). Revisiting the Role of Plant Transcription

Factors in the Battle against Abiotic Stress. https://doi.org/10.3390/ijms19061634

Kim, C.Y., Vo, K.T.X., Nguyen, C.D., Jeong, D.H., Lee, S.K., Kumar, M., Kim, S.R., Park, S.H., Kim, K., Jeon, S. (2016). Functional analysis of a cold-responsive rice WRKY gene, OsWRKY71. Plant Biotechnol. 10, 13-23. doi: 10.1007/s11816-015-0383-2

Kim SH, Hong JK, Lee SC, Sohn KH, Jung HW, Hwang BK. (2004). CAZFP1, Cys2/His2-type zinc-finger transcription factor gene functions as a pathogen-induced early-defense gene in Capsicum annuum. Plant Mol Biol; 55:883-904.

Kim, Y. G., Cha, J., and Chandrasegaran, S. (1996). Hybrid restriction enzymes: zinc finger fusions to Fok I cleavage domain. Proc. Natl. Acad. Sci. U.S.A. 93, 1156-1160. doi: 10.1073/pnas.93.3.1156

Kizis, D., \& Investigacio, C. De. (2002). Maize DRE-binding proteins $D B F 1$ and $D B F 2$ are involved in rab17 regulation through the drought-responsive element in an ABAdependent pathway. The Plant Journal 30: 679-689.

Koryachko, A., Matthiadis, A., Ducoste, J. J., Tuck, J., Long, T. A., \& Williams, C. (2015). Computational approaches to identify regulators of plant stress response using high- 
throughput gene expression data. Current Plant Biology, 3-4, 20-29. https://doi.org/10.1016/j.cpb.2015.04.001

Kusano T, Berberich T, Harada M, Suzuki N, Sugawara K (1995) A maize DNA-binding factor with a bZIP motif is induced by low temperature. Mol Gen Genet 248: 507-517.

Lan, X., Hoang, T., Ngoc, D., Nhi, H., Binh, N., Thu, A., Tran, L. P. (2017). Transcription Factors and Their Roles in Signal Transduction in Plants under Abiotic Stresses, 483497. https://doi.org/10.2174/1389202918666170227150057

Lata, C., Yadav, A., \& Prasad, M. (2007). Role of Plant Transcription Factors in Abiotic Stress Tolerance. Physiological, Biochemical and Genetic Perspectives; www.intechopen.com

Le, D. T., Nishiyama, R., Watanabe, Y., Mochida, K., Yamaguchi-Shinozaki, K., Shinozaki, K., \& Tran, L.-S. P. (2011). Genome-Wide Survey and Expression Analysis of the PlantSpecific NAC Transcription Factor Family in Soybean During Development and Dehydration Stress. DNA Research: An International Journal for Rapid Publication of Reports on Genes and Genomes, 18(4), 263-276. http://doi.org/10.1093/dnares/dsr015

Lee, E.A. and Tollenaar, M. (2007) Physiological basis of successful breeding strategies for maize grain yield.Crop Sci.47, S202-S215.

Lee, Y.-H., Oh, H.-S., Cheon, C.-I., Hwang, I.-T., Kim, Y.-J., \& Chun, J.-Y. (2001) Structure and expression of the Arabidopsis thaliana homeobox gene Athb-12. Biochem Biophys Res Commun 284: 133-141.

Li Z, Srivastava R, Tang J, Zheng Z and Howell SH (2018) Cis-Effects Condition the Induction of a Major Unfolded Protein Response Factor, ZmbZIP60, in Response to Heat Stress in Maize. Front. Plant Sci. 9:833. doi: 10.3389/fpls.2018.00833

Li P, Cao W, Fang H, Xu S, Yin S, Zhang Y, Lin D, Wang J, Chen Y, Xu C and Yang Z (2017) Transcriptomic Profiling of the Maize (Zea mays L.) Leaf Response to Abiotic Stresses at the Seedling Stage. Front. Plant Sci. 8:290. doi: 10.3389/fpls.2017.00290

Li, H. C., Zhang, H. N., Li, G. L., Liu, Z. H., Zhang, Y. M., Zhang, H. M., \& Guo, X. L. (2015). Expression of maize heat shock transcription factor gene ZmHsfo6 enhances the thermotolerance and drought-stress tolerance of transgenic Arabidopsis. Functional Plant Biology, 42(11), 1080-1091. https://doi.org/10.1071/FP15080

Li, H., Gao, Y., Xu, H., \& Dai, Y. (2013). ZmWRKY33, a WRKY maize transcription factor conferring enhanced salt stress tolerances in Arabidopsis, 207-216. https://doi.org/10.1007/s10725-013-9792-9

Li Q, Yang X, Xu S, Cai Y, Zhang D, Han Y, Li L, Zhang Z, Gao S, Li J, Yan J. (2012) Genome-wide association studies identified three independent polymorphisms associated with alphatocopherol content in maize kernels. PLoS One 7: e36807

Lin, H., Liu, Q., Li, X., Yang, J., Liu, S., Huang, Y., Schnable, P. S. (2017). Substantial contribution of genetic variation in the expression of transcription factors to phenotypic variation revealed by eRD-GWAS, 1-14. https://doi.org/10.1186/s13059-017-1328-6 
1333

1334

1335

1336

1337

1338

1339

1340

1341

1342

1343

1344

1345

1346

1347

1348

1349

1350

1351

1352

1353

1354

1355

1356

1357

1358

1359

1360

1361

1362

1363

1364

1365

1366

1367

1368

1369

1370

1371

1372

1373

Lin, Y., Jiang, H., Chu, Z., Tang, X., Zhu, S., \& Cheng, B. (2011). Genome-wide identification , classification and analysis of heat shock transcription factor family in maize.BMC Genomics 2011,12:76 http://www.biomedcentral.com/1471-2164/12/76

Lin, Z., Hong, Y., Yin, M., Li, C., Zhang, K. and Grierson, D. (2008) A tomato HD-Zip homeobox protein, LeHB-1, plays an important role in floral organogenesis and ripening. Plant J.55: 301-310.

Liu, B., Hong, Y.B., Zhang, Y.F., Li, X.H., Huang, L., Zhang, H.J., Li, D.Y., Song, F.M. (2014a). Tomato WRKY transcriptional factor SlDRW1 is required for disease resistance against Botrytis cinerea and tolerance to oxidative stress. Plant Sci. 227, 145-156. https://doi.org/10.1016/j.plantsci.2014.08.001

Liu, T. K., Song, X. M., Duan, W. K., Huang, Z. N., Liu, G. F., Li, Y., Hou, X. (2014b). Genome- wide analysis and expression patterns of NAC transcription factor family under different developmental stages and abiotic stresses in Chinese Cabbage. Plant Mol. Biol. Report. 32, 1041-1056. doi: 10.1007/s11105-014-0712-6

Liu, S., Wang, X., Wang, H., Xin, H., Yang, X., Yan, X., Li, J., Tran, L.P, Shinozaki, K., Qin, F. (2013) Genome-Wide Analysis of ZmDREB Genes and Their Association with Natural Variation in Drought Tolerance at Seedling Stage of Zea maysL.. PLoS Genet 9(9): e1003790. doi:10.1371/journal.pgen.1003790

Liu, L., Hao, Z., Weng, J., Li, M., Zhang, D., Bai, L., \& Wang, L. (2012). Identication of drought-responsive genes by cDNA-amplied fragment length polymorphism in maize, Annals of Applied Biology, https://doi.org/10.1111/j.1744-7348.2012.00565.x

Liu C., Ruan Y., Lin Z., Wei R., Peng Q., Guan C., Ishii H. (2008). Antagonism between acibenzolar-S-methyl-induced systemic acquired resistance and jasmonic acid-induced systemic acquired susceptibility to Colletotrichum orbiculare infection in cucumber. Physiol. Mol. Plant Pathol. 72:141-145. doi: 10.1016/j.pmpp.2008.08.001.

Liu Q, Kasuga M, Sakuma Y, Abe H, Miura S, Yamaguchi-Shinozaki K, Shinozaki K. (1998). Two transcription factors, DREB1 and DREB2, with an EREBP/AP2 DNA binding domain separate two cellular signal transduction pathways in drought- and low temperature-responsive gene expression, respectively, in Arabidopsis. Plant Cell; 10:1391-1406.

Loredana F. Ciarmiello, Pasqualina Woodrow, Amodio Fuggi, Giovanni Pontecorvo and Petronia Carillo (2011). Plant Genes for Abiotic Stress, Abiotic Stress in Plants Mechanisms and Adaptations, Prof. Arun Shanker (Ed.), ISBN: 978-953-307-394-1, InTech, Available from: http:/www.intechopen.com/books/abioticstress-in-plantsmechanisms-and-adaptations/plant-genes-for-abiotic-stress

Lowder, L. G., Zhou, J., Zhang, Y., Malzahn, A., Zhong, Z., Hsieh, T. F., Qi, Y. (2018). Robust Transcriptional Activation in Plants Using Multiplexed CRISPR-Act2.0 and mTALE-Act Systems. Molecular Plant, 11(2), 245-256. https://doi.org/10.1016/j.molp.2017.11.010

Lu., M, Sun., QP, Zhang., DF, Wang., T, Pan., T. (2015) Identification of 7 stress related NAC transcription factor members in maize (Zea mays L.) and characterization of the

Peer) reviewing PDF | (2019:02:35201:1:2:REVIEW 9 May 2019) 
expression pattern of these genes, Biochemical and Biophysical Research Communications, doi: 10.1016/j.bbrc.2015.04.113.

Lu, M., Ying, S., \& Shi, D. Z. Y. (2012). A maize stress-responsive NAC transcription factor, ZmSNAC1, confers enhanced tolerance to dehydration in transgenic Arabidopsis, 17011711. https://doi.org/10.1007/s00299-012-1284-2

Luan, M., Xu, M., Lu, Y., Zhang, L., Fan, Y., \& Wang, L. (2014). Expression of zma-miR169 miRNAs and their target ZmNF-YA genes in response to abiotic stress in maize leaves. Gene, 1-8. https://doi.org/10.1016/j.gene.2014.11.001

Ma, H., Liu, C., Li, Z., Ran, Q., Xie, G., Wang, B., Fang, S., Chu, J., ... Zhang, J. (2018). ZmbZIP4 Contributes to Stress Resistance in Maize by Regulating ABA Synthesis and Root Development. Plant physiology, 178(2), 753-770.

Ma, X., Zhu, X., Li, C., Song, Y., Zhang, W., Xia, G., \& Wang, M. (2015). Overexpression of wheat NF-YA10 gene regulates the salinity stress response in Arabidopsis thaliana. Plant Physiol. Biochem. 86, 34-43. doi: 10.1016/j.plaphy. 2014.11.011

Mahalingam, R. (ed.) (2015). "Consideration of combined stress: a crucial paradigm for improving multiple stress tolerance in plants," in Combined Stresses in Plants, (Cham: Springer International Publishing), 1-25. doi: 10.1007/978-3-319-07899-1_1

Manavella, P. A., Arce, A. L., Dezar, C. A., Bitton, F., Renou, J.-P., Crespi, M., \& Chan, R. L. (2006) Cross- talk between ethylene and drought signaling pathways is mediated by the sunflower Hahb-4 transcription factor. Plant J.48: 125-137.

Mantovani, R. (1999). The molecular biology of the CCAAT-binding factor NF-Y. Gene 239, 15-27. doi: 10.1016/S0378-1119(99)00368-6

Mao, H., Yu, L., Han, R., Li, Z., \& Liu, H. (2016). Plant Physiology and Biochemistry ZmNAC55, a maize stress-responsive NAC transcription factor, confers drought resistance in transgenic Arabidopsis. Plant Physiology et Biochemistry, 105, 55-66. https://doi.org/10.1016/j.plaphy.2016.04.018

Mao, H., Wang, H., Liu, S., Li, Z., Yang, X., Yan, J., Li, J., Tran LS, Qin, F. (2015). A transposable element in a NAC gene is associated with drought tolerance in maize seedlings. Nature Communications. 6: $\quad$ 8326. https://doi.org/10. 1038/ncomms9326 PMID: 26387805.

Margolin, A. A., Nemenman, I., Basso, K., Wiggins, C., Stolovitzky, G., Favera, R. D., \& Califano, A. (2006). ARACNE : An Algorithm for the Reconstruction of Gene Regulatory Networks in a Mammalian Cellular Context. BMC Bioinform. 7 (1) 15, 1-15. https://doi.org/10.1186/1471-2105-7-S1-S7

M'mboyi F, Mugo S, Mwimali M, Ambani L. (2010) Maize Production and Improvement in Sub-Saharan Africa. Nairobi: African Biotechnology Stakeholders Forum (ABSF).

Misra, A., \& Sriram, G. (2013). Network component analysis provides quantitative insights on an Arabidopsis transcription factor-gene regulatory network. BMC Systems Biology, 7, 126. http://doi.org/10.1186/1752-0509-7-126 
1414

1415

1416

1417

1418

1419

1420

1421

1422

1423

1424

1425

1426

1427

1428

1429

1430

1431

1432

1433

1434

1435

1436

1437

1438

1439

1440

1441

1442

1443

1444

1445

1446

1447

1448

1449

1450

1451

1452

Mittler, R. (2006). Abiotic stress, the field environment and stress combination. Trends Plant Sci. 11, 15-19. doi: 10.1016/j.tplants.2005. 11.002

Moon, S.J., Han, S.Y., Kim, D.Y., Yoon, I.S., Shin, D., Byun, M.O., Kwon, H.B., Kim, B.G. (2015) Ectopic expression of a hot pepper bZIP-like transcription factor in potato enhances drought tolerance without decreasing tuber yield. Plant Mol. Biol. 89, 421-431. doi: 10.1007/s11103-015-0378-y.

Nakashima K, Ito Y, Yamaguchi-Shinozaki K (2009) Transcriptional Regulatory Networks in Response to Abiotic Stresses in Arabidopsis and Grasses. Plant Physiology 149: 88- 95.

Nardini, M., Gnesutta, N., Donati, G., Gatta, R., Forni, C., Fossati, A., Vonrhein,C., Moras, D., Romier, M., Matovani, R. (2013). Sequence-specific transcription factor NF-Y displays histone-like DNA binding and H2B-like ubiquitination. Cell 152, 132-143. doi: 10.1016/j.cell.2012.11.047

Nelson DE, Repetti PP, Adams TR, Creelman RA, Wu J, Warner DC, Anstrom DC, Bensen RJ, Castiglioni PP, Donnarummo MG, Hinchey BS, Kumimoto RW, Maszle DR, Canales RD, Krolikowski KA, Dotson SB, Gutterson N, Ratcliffe OJ, Heard JE. (2007). Plant nuclear factor Y (NF-Y) B subunits confer drought tolerance and lead to improved corn yields on water-limited acres. Proc Natl Acad Sci USA; 104:16450-16455.

Nepolean T, Kaul J, Mukri G and Mittal S (2018) Genomics-Enabled Next-Generation Breeding Approaches for Developing System-Specific Drought Tolerant Hybrids in Maize. Front. Plant Sci. 9:361. doi: 10.3389/fpls.2018.00361

Ni Y, Aghamirzaie D, Elmarakeby H, Collakova E, Li S, Grene R and Heath LS (2016) A Machine Learning Approach to Predict Gene Regulatory Networks in Seed Development in Arabidopsis. Front. Plant Sci. 7:1936. doi: 10.3389/fpls.2016.01936

Nuruzzaman, M., Manimekalai, R., Sharoni, A. M., Satoh, K., Kondoh, H., Ooka, H., kikuchi, S. (2010). Genome-wide analysis of NAC transcription factor family in rice. Gene 465, 3044. doi: 10.1016/j.gene.2010.06.008

Ogawa., O, Yamaguchi., K and Nishiuchi., T. (2007) "High-level overexpression of the Arabidopsis HsfA2 gene confers not only increased themotolerance but also salt/osmotic stress tolerance and enhanced callus growth, "Journal of Experimental Botany, vol. 58, no. 12, pp. 3373-3383.

Ooka H, Satoh K, Doi K, Nagata T, Otomo Y, Murakami K, Matsubara K, Osato N, Kawai J, Carninci P, Hayashizaki Y, Suzuki K, Kojima K, Takahara Y, Yamamoto K, Kikuchi S (2003) Comprehensive analysis of NAC family genes in Oryza sativa and Arabidopsis thaliana. DNA Res 10:239-247

Pandey, P., Ramegowda, V., and Senthil-Kumar, M. (2015). Shared and unique responses of plants to multiple individual stresses and stress combinations: physiological and molecular mechanisms. Front. Plant Sci. 6:723. doi: 10.3389/ fpls.2015.00723

Park, M.Y., Kim, S.A., Lee, S.J. and Kim, S.Y. (2013) ATHB17 is a positive regulator of abscisic acid response during early seedling growth. Mol. Cells, 35, 125-133. 
1453

1454

1455

1456

1457

1458

1459

1460

1461

1462

1463

1464

1465

1466

1467

1468

1469

1470

1471

1472

1473

1474

1475

1476

1477

1478

1479

1480

1481

1482

1483

1484

1485

1486

1487

1488

1489

1490

1491

1492

Paz-Ares J, Ghosal D, Wienand U, Peterson PA, Saedler H (1987) The regulatory cl locus of Zea mays encodes a protein with homology to myb proto-oncogene products and with structural similarities to transcriptional activators. EMBO f. 6: 3553-3558.

Pérez-Rodríguez P, Riaño-Pachón DM, Corrêa LG, Rensing SA, Kersten B, Mueller-Roeber B (2010) PlnTFDB: updated content and new features of the plant transcription factor database. Nucl Acids Res 38:D822-D8227

Perlack, R.D., Wright, L.L., Turhollow, A.F., Graham, R.L., Stokes, B.J. and Erbach, D.C. (2005) Biomass as Feedstock for a Bioenergy and Bioproducts Industry: The Technical Feasibility of a Billion-Ton Annual Supply. Oak Ridge, TN: Oak Ridge National Laboratory.

Phukan UJ, Jeena GS and Shukla RK (2016) WRKY Transcription Factors: Molecular Regulation and Stress Responses in Plants. Front. Plant Sci. 7:760. doi: 10.3389/fpls.2016.00760

Phukan, U.J., Mishra, S., Timbre, K., Luqman, S., and Shukla, R.K. (2014). Mentha arvensis exhibit better adaptive characters in contrast to Mentha piperita when subjugated to sustained water logging stress. Protoplasma 251, 603-614.doi: 10.1007/s00709-0130561-4

Prasad, P. V. V., Pisipati, S. R., Momcilovic, I., and Ristic, Z. (2011). Independent and combined effects of high temperature and drought stress during grain filling on plant yield and chloroplast EF-Tu expression in spring wheat. J. Agron. Crop Sci. 197, 430-441. doi: 10.1111/j.1439-037X.2011.00477.x

Qin, F., Kakimoto, M., Sakuma, Y., Maruyama, K., Osakabe, Y., Tran, L.-S. P., YamaguchiShinozaki, K. (2007). Regulation and functional analysis of ZmDREB2A in response to drought and heat stresses in Zea mays L. The Plant Journal, 50(1), 54-69. doi:10.1111/j.1365-313x.2007.03034.x

Qin F, Sakuma Y, Li J, Liu Q, Li Y, Shinozaki K, Yamaguchi-Shinozaki K (2004) Cloning and Functional Analysis of a Novel $D R E B 1 / C B F$ Transcription Factor Involved in ColdResponsive Gene Expression in Zea mays L. Plant Cell Physiol. 45(8): 1042-1052 (2004)

Qing, M and Wei, D. (2018). Functional Analysis of Mam-Resistant Candidate Gene Zmhdz12. Science Online.

Rabara, R. C., Tripathi, P., \& Rushton, P. J. (2014). The potential of transcription factor-based genetic engineering in improving crop tolerance to drought. Omics: a journal of integrative biology, 18(10), 601-14.

Ramakrishna, C., Singh, S., Raghavendrarao, S., Padaria, J. C., Mohanty, S., Sharma, T. R., Solanke, A.U. (2018). The membrane tethered transcription factor EcbZIP17 from finger millet promotes plant growth and enhances tolerance to abiotic stresses. Sci. Rep. 8:2148. doi: 10.1038/s41598-018-19766-4

Ramegowda, V., and Senthil-Kumar, M. (2015). The interactive effects of simultaneous biotic and abiotic stresses on plants: mechanistic understanding from drought and pathogen combination. J. Plant Physiol. 176, 47-54. doi: 10.1016/j.jplph.2014.11.008 
1493

1494

1495

1496

1497

1498

1499

1500

1501

1502

1503

1504

1505

1506

1507

1508

1509

1510

1511

1512

1513

1514

1515

1516

1517

1518

1519

1520

1521

1522

1523

1524

1525

1526

1527

1528

1529

1530

1531

1532

Rasmussen S., Barah P., Suarez-Rodriguez M.C., Bressendorff S., Friis P., Costantino P., Bones A.M., Nielsen H.B., Mundy J. (2013). Transcriptome responses to combinations of stresses on Arabidopsis. Plant Physiol. 161:1783-1794. doi: 10.1104/pp.112.210773.

Renau-Morata, B., Molina, R. V., Carrillo, L., Cebolla-Cornejo, J., Sánchez-Perales, M., Pollmann, S., Nebauer, S. G. (2017). Ectopic Expression of CDF3 Genes in Tomato Enhances Biomass Production and Yield under Salinity Stress Conditions. Frontiers in Plant Science, 8, 660. http://doi.org/10.3389/fpls.2017.00660

Riechmann JL, Heard J, Martin G, Reuber L, Jiang CZ, Keddie J, Adam L, Pineda O, Ratcliffe OJ, Samaha RR, Crelman R, Pilgrim M, Broun P, Zhang JZ, Ghandehari D, Sherman BK, Yu GL. (2000). Arabidopsis transcription factors: genome-wide comparative analysis among eukaryotes. Science; 290:2105-2110.

Riechmann, J. L., and Meyerowitz, E. M. (1998). The AP2/EREBP family of plant transcription factors. Biol. Chem. 379, 633-646.

Rice, E. A., Khandelwal, A., Creelman, R. A., Griffith, C., Ahrens, J. E., Taylor, J. P., ... Loida, P. J. (2014). Expression of a truncated ATHB17 protein in maize increases ear weight at silking. PloS one, 9(4), e94238. doi:10.1371/journal.pone.0094238

Rushton PJ, Somssich IE, Ringler P, Shen QXJ (2010) WRKY transcription factors. Trends Plant Sci 15:247-258

Rushton, P. J., Bokowiec, M. T., Han, S., Zhang, H., Brannock, J. F., Chen, X., Laudeman, T. W., ... Timko, M. P. (2008). Tobacco transcription factors: novel insights into transcriptional regulation in the Solanaceae. Plant physiology, 147(1), 280-95.

Saibo NJM, Lourenc, o T, Oliveira MM (2009) Transcription factors and regulation of photosynthetic and related metabolism under environmental stresses. Annals of Botany 103: 609-623.

Sakuma Y, Maryyama K, Qin F, Osakabe Y, Shinozaki K, Yamaguchi-Shinozaki K. (2006) Dual function of an Arabidopsis transcription factor DREB2A in water-stress-responsive and heat-stress-responsive gene expression. Proc Nat Acad Sci USA 2006;103:18822-18827.

Saleh A, Lumreras V, Pages M (2005) Functional role of DRE binding transcription factors in abiotic stress. In: Tuberosa R, Phillips RL, Gale M (eds) Proceedings of the International Congress 'In the Wake of the Double Helix From the Green Revolution to the Gene Revolution', 27-31 May 2003, Bologna, Italy, 193-205, 2005 Avenue media. Italy, Bologna

Sato, H., Mizoi, J., Tanaka, H., Maruyama, K., Qin, F., Osakabe, Y., Morimoto, K., Ohori, T., Kusakabe, K., Nagata, M., Shinozaki, K., Yamaguchi-Shinozaki, K. (2014). Arabidopsis DPB3-1, a DREB2A interactor, specifically enhances heat stress induced gene expression by forming a heat stress-specific transcriptional complex with NF-Y subunits. Plant Cell 26, 4954-4973. doi: 10.1105/tpc.114. 132928

Scharf., K, Berberich., T, Ebersberger., I, and Nover., L. (2012). Plant heat stress transcription factor (Hsf) family: structure, function and evolution, Biochimica et Biophysica Acta-Gene Regulatory Mechanisms, vol. 1819, no. 2, pp. 104-119.

Peer) reviewing PDF | (2019:02:35201:1:2:REVIEW 9 May 2019) 
1533

1534

1535

1536

1537

1538

1539

1540

1541

1542

1543

1544

1545

1546

1547

1548

1549

1550

1551

1552

1553

1554

1555

1556

1557

1558

1559

1560

1561

1562

1563

1564

1565

1566

1567

1568

1569

1570

1571

Scharf KD, Rose S, Zott W, SchöfflF, Nover L. (1990) Three tomato genes code for heat stress transcription factors with a region of remarkable homology to the DNA-binding domain of the yeast HSF.EMBO Journal 9, 4495-4501.

Schnable, P. S., Ware, D., Fulton, R. S., Stein, J. C., Wei, F., Pasternak, S., ... Graves, T. A. (2009). The B73 Maize Genome: Complexity, Diversity, and Dynamics. Science, 326(5956), 1112-1115. doi:10.1126/science.1178534.

Schuetz, T., Gallo, G., Sheldon H., empst P., Kingston R. (1991) "Isolation of a cDNA for HSF2: Evidence for two heat shock factor genes in humans," Proceedings of the National Academy of Sciences of the United States of America, vol. 88, no. 16, pp. 6911-6915.

Sekhon, R.S., Lin H, Childs K.L., Hansey C.N., Buell C.R., de Leon N., Kaeppler S.M. (2011) Genome-wide atlas of transcription during maize development The Plant Journal 66, 553-563 doi: $10.1111 / j .1365-313 X .2011 .04527$.

Shang Y, Yan L, Liu Z-Q, Cao Z, Mei C, Xin Q, Wu F-Q, Wang X-F, Du S-Y, Jiang T, Zhang X-F, Zhao R, Sun H-L, Liu R, Yu Y-T, Zhang D-P (2010) The Mg-chelatase H subunit of Arabidopsis antagonizes a group of WRKY transcription repressors to relieve ABAresponsive genes of inhibition. Plant Cell 22:1909-1935

Shao, H., Wang, H and Tang, X. (2015) NAC transcription factors in plant multiple abiotic stress responses: progress and prospects. Front. Plant Sci. 6:902. doi: 10.3389/fpls.2015.00902

Shen, Q., Zhang, P., Ho T-HD (1996) Modular nature of abscisic acid (ABA) response complexes: composite promoter units that are necessary and sufficient for $\mathrm{ABA}$ induction of gene expression in barley. Plant Cell 8:1107-1119

Shim, D., Hwang, J.U, Lee, J, Lee, S, Choi, Y. (2009) Orthologs of the class A4 heat shock transcription factor HSFA4a confer cadmium tolerance in wheat and rice. The Plant Journal21, 4031-4043.

Shinozaki, K., \& Yamaguchi-Shinozaki, K. (2006). Gene networks involved in drought stress response and tolerance. Journal of Experimental Botany, 58(2), 221-227. doi:10.1093/jxb/erl164

Shinozaki K, Yamaguchi-Shinozaki K, Seki M. (2003). Regulatory network of gene expression in the drought and cold stress responses. Curr Opin Plant Biol; 6:410-417.

Shiriga, K., Sharma, R., Kumar, K., \& Kumar, S. (2014). Genome-wide identification and expression pattern of drought-responsive members of the NAC family in maize. MGENE, 2, 407-417. https://doi.org/10.1016/j.mgene.2014.05.001

Siefers, N., Dang, K. K., Kumimoto, R. W., Bynum, W. E., Tayrose, G., Holt, B. F. (2009).

Tissue-specific expression patterns of Arabidopsis NF-Y transcription factors suggest

potential for extensive combinatorial complexity. Plant Physiol. 149, 625-641. doi:

$10.1104 /$ pp. 108.130591

Singh K, Foley RC, Oñate-Sánchez L. (2002). Transcription factors in plant defense and stress responses. Curr Opin Plant Biol.5:430-436.

Peer) reviewing PDF | (2019:02:35201:1:2:REVIEW 9 May 2019) 
1572

1573

1574

1575

1576

1577

1578

1579

1580

1581

1582

1583

1584

1585

1586

1587

1588

1589

1590

1591

1592

1593

1594

1595

1596

1597

1598

1599

1600

1601

1602

1603

1604

1605

1606

1607

1608

1609

1610

Soderman E, Hjellstrom M, Fahleson J, Engstrom P (1999) The HD-Zip gene ATHB6 in Arabidopsis is expressed in developing leaves, roots and carpels and up-regulated by water deficit conditions. Plant Mol Biol 40: 1073-1083.

Soderman E, Mattsson J, Engstrom P (1996) The Arabidopsis homeobox gene ATHB-7 is induced by water deficit and by abscisic acid. Plant J 10: 375-381

Song,X., Li,Y., and Hou,X.(2013). Genome-wide analysis of the AP2/ERF transcription factor super family in Chinese cabbage (Brassicarapa ssp. pekinensis). BMC Genomics 14:573. doi:10.1186/1471-2164-14-573

Su, H., Cao, Y., Ku, L., Yao, W., Cao, Y., Ren, Z., ... Chen, Y. (2018). Dual functions of $Z m N F-Y A 3$ in photoperiod-dependent flowering and abiotic stress responses in maize. Journal of Experimental Botany. doi:10.1093/jxb/ery299

Sun, X.C., Gao, Y.F., Li, H.-R., Yang, S.Z., Liu, Y.S. (2015) .Over-expression of SlWRKY39 leads to enhanced resistance to multiple stress factors in tomato. J. Plant Biol. 58, 52-60. doi: http://sci-hub.tw/10.1007/s12374-014-0407-4

Sun H, Huang X, Xu X, Lan H, Huang J, Zhang, HS, (2012) ENAC1, a NAC transcription factor, is an early and transient response regulator induced by abiotic stress in rice (Oryza sativa L.). Mol Biotechnol 52:101-110

Suzuki, N., Rivero, R. M., Shulaev, V., Blumwald, E., and Mittler, R. (2014). Abiotic and biotic stress combinations. New Phytol. 203, 32-43. doi: 10.1111/nph. 12797

Svitashev, S., Schwartz, C., Lenderts, B., Young, J. K., \& Cigan, A. M. (2016). Genome editing in maize directed by CRISPR - Cas9 ribonucleoprotein complexes: 13274, Nature Communications. 1-20.

Tang W., Harris L. \& Newton R.J. (2003). Molecular mechanism of salinity stress and biotechnological strategies for engineering salt tolerance in plants. Forestry Studies in China, 5(2), 52-62

Tello-Ruiz, M. K., Naithani, S., Stein, J. C., Gupta, P., Campbell, M., Olson, A., Ware, D. (2018). Gramene 2018: unifying comparative genomics and pathway resources for plant research. Nucleic Acids Research, 46 (Database issue), D1181-D1189. http://doi.org/10.1093/nar/gkx1111

Tenaillon, M. I., Sawkins, M. C., Long, A. D., Gaut, R. L., Doebley, J. F., \& Gaut, B. S. (2001). Patterns of DNA sequence polymorphism along chromosome 1 of maize (Zea mays ssp. mays L.). Proceedings of the National Academy of Sciences of the United States of America, 98(16), 9161-9166. doi:10.1073/pnas.151244298.

Todaka, D., Shinozaki, K., and Yamaguchi-Shinozaki, K. (2015). Recent advances in the dissection of drought-stress regulatory networks and strategies for development of drought-tolerant transgenic rice plants. Front. Plant Sci. 6:84. doi: 10.3389/fpls.2015.00084

Tran L-SP, Nakashima K, Sakuma Y, Osakabe Y, Qin F, Simpson SD, Maruyama K, Fujita Y, Shinozaki K, Yamaguchi-Shinozaki K (2007) Co-expression of the stress-inducible zinc 
finger homeodomain $Z F H D 1$ and NAC transcription factors enhances expression of the ERDI gene in Arabidopsis. Plant J 49:46-63

Tripathi P, Rabara RC, Rushton PJ (2014) A systems biology perspective on the role of WRKY transcription factors in drought responses in plants. Planta 239:255-266

Ulker B, Somssich IE (2004) WRKY transcription factors: from DNA binding towards biological function. Curr Opin Plant Biol 7:491-498

Ullah, A., Sun, H., Yang, X., Zhang, X. (2017). A novel cotton WRKY gene, GhWRKY6-like, improves salt tolerance by activating the ABA signaling pathway and scavenging of reactive oxygen species. Physiol. Plant. 162, 439-454. https://doi.org/10.1111/ppl.12651.

Umezawa T, Fujita M, Fujita Y, Yamaguchi-Shinozaki K, and Shinozaki K (2006) Engineering drought tolerance in plants: discovering and tailoring genes to unlock the future. Current Opinion in Biotechnology 17: 113-122.

Vermeirssen, V., Clercq, I. De, Parys, T. Van, Breusegem, F. Van, \& Peer, Y. Van De. (2014). Arabidopsis Ensemble Reverse-Engineered Gene Regulatory Network Discloses Interconnected Transcription Factors in Oxidative Stress. Plant Cell, tpc-114. https://doi.org/10.1105/tpc.114.131417

Vinocur B, and Altman A. (2005). Recent advances in engineering plant tolerance to abiotic stress: Achievements and limitations. Curr Opin Biotech 16, 123-132.

Wang, C. T., Ru, J. N., Liu, Y. W., Yang, J. F., Li, M., Xu, Z. S., \& Fu, J. D. (2018). The Maize WRKY Transcription Factor ZmWRKY40 Confers Drought Resistance in Transgenic Arabidopsis. International journal of molecular sciences, 19(9), 2580. doi:10.3390/ijms 19092580

Wang B, Li Z, Ran Q, Li P, Peng Z and Zhang J. (2018b) ZmNF-YB16 Overexpression Improves Drought Resistance and Yield by Enhancing Photosynthesis and the Antioxidant Capacity of Maize Plants. Front. Plant Sci. 9:709. doi: 10.3389/fpls.2018.00709

Wang C.-T., Ru, J.-N., Liu, Y.-W., Li, M., Zhao, D., Yang, J.-F., ... Xu, Z.-S. (2018c). Maize WRKY Transcription Factor ZmWRKY106 Confers Drought and Heat Tolerance in Transgenic Plants. International Journal of Molecular Sciences, 19(10), 3046. doi:10.3390/ijms19103046

Wang C., Lu, G., Hao, Y., Guo, H., Guo, Y., Zhao, J., \& Cheng, H. (2017). ABP9, a maize bZIP transcription factor, enhances tolerance to salt and drought in transgenic cotton. Planta, 246(3), 453-469. https://doi.org/10.1007/s00425-017-2704-X

Wang D., Yanchong Y., Liu., Z, Shuo., L, Wang., Z, Xiang., F. (2016a) Membrane-bound NAC transcription factors in maize and their Contribution to the oxidative stress response, Plant Science http://dx.doi.org/10.1016/j.plantsci.2016.05.019

Wang H, Shao H and Tang X (2016b) Recent Advances in Utilizing Transcription Factors to Improve Plant Abiotic Stress Tolerance by Transgenic Technology.Front.PlantSci.7:67. doi: $10.3389 /$ fpls.2016.00067 
1649

1650

1651

1652

1653

1654

1655

1656

1657

1658

1659

1660

1661

1662

1663

1664

1665

1666

1667

1668

1669

1670

1671

1672

1673

1674

1675

1676

1677

1678

1679

1680

1681

1682

1683

1684

1685

1686

1687

1688

Wang, Z., Su, G., Li, M., Ke, Q., Kim, S. Y., Li, H., ... Kwak, S.-S. (2016). Overexpressing Arabidopsis ABF3 increases tolerance to multiple abiotic stresses and reduces leaf size in alfalfa. Plant Physiology and Biochemistry, 109, 199-208. doi:10.1016/j.plaphy.2016.09.020

Wang N (2014). Analysis of Abiotic Stress Related Functions of Genes ZmWRKY50 and ZmWRKY44 in Maize (Zea Mays L.).Globe Thesis, 2180330485996209

Wang, C., Shi, X., Liu, L., Li, H., Ammiraju, J. S., Kudrna, D. A., ... Luo, M. (2013). Genomic resources for gene discovery, functional genome annotation, and evolutionary studies of maize and its close relatives. Genetics, 195(3), 723-737. doi:10.1534/genetics.113.157115

Wang B., Zheng, J., Liu, Y., Wang, J., \& Wang, G. (2012). Cloning and characterization of the stress-induced bZIP gene ZmbZIP60 from maize. Molecular Biology Reports, 39(5), 6319-6327. https://doi.org/10.1007/s11033-012-1453-y

Wang CT, Yang QA, Yang YM. (2011) Characterization of the ZmDBP4 gene encoding a CRT/DRE-binding protein responsive to drought and cold stress in maize. Acta Physiologiae Plantarum. 33: 575 \pm 583. https://doi.org/10.1007/s11738-010-0582-y

Wang, W., Vinocur, B., Shoseyov, O., \& Altman, A. (2004). Role of plant heat-shock proteins and molecular chaperones in the abiotic stress response. Trends in Plant Science, 9(5), 244-252. doi:10.1016/j.tplants.2004.03.006

Wang W.X., Barak T., Vinocur B., Shoseyov O. \& Altman A. (2003). Abiotic resistance and chaperones: possible physiological role of SP1, a stable and stabilizing protein from Populus. In: Vasil IK (ed.) Plant biotechnology 2000. Kluwer, Dordrecht, pp 439-43

Waters, A. J., Makarevitch, I., Noshay, J., Burghardt, L. T., Hirsch, C. N., Hirsch, C. D., \& Springer, N. M. (2017). Natural variation for gene expression responses to abiotic stress in maize. Plant Journal, 89(4), 706-717. https://doi.org/10.1111/tpj.13414

Wei, H., Zhao, H., Su, T., Bausewein, A., Greiner, S., Harms, K., \& Rausch, T. (2017). Chicory R2R3-MYB transcription factors CiMYB5 and CiMYB3 regulate fructan 1-exohydrolase expression in response to abiotic stress and hormonal cues. Journal of Experimental Botany, 68(15), 4323-4338. http://doi.org/10.1093/jxb/erx210

Wei, T., Deng, K., Liu, D., Gao, Y., Liu, Y., Yang, M., Zhang, L., Zheng, X., Wang, C., Song, W., Chen, C., Zhang, Y. (2016). Ectopic Expression of DREB Transcription Factor, AtDREB 1A, confers tolerance to drought in transgenic Salvia miltiorrhiza. Plant Cell Physiol. 57, 1593-1609. https://doi.org/10.1093/pcp/pcw084

Wei, K. A., Chen, J. U. A. N., Wang, Y. A., Chen, Y. A., Chen, S. H., Lin, Y. I. N. A., ... Zhong, X. I. (2012a). Genome-Wide Analysis of bZIP-Encoding Genes in Maize, (October), DNA Research 19, 463-476. doi:10.1093/dnares/dss026.

Wei, K.-F., Chen, J., Chen, Y.-F., Wu, L.-J., \& Xie, D.-X. (2012b). Molecular Phylogenetic and Expression Analysis of the Complete WRKY Transcription Factor Family in Maize. DNA Research: An International Journal for Rapid Publication of Reports on Genes and Genomes, 19(2), 153-164. http://doi.org/10.1093/dnares/dsr048

Peer] reviewing PDF | (2019:02:35201:1:2:REVIEW 9 May 2019) 
1689

1690

1691

1692

1693

1694

1695

1696

1697

1698

1699

1700

1701

1702

1703

1704

1705

1706

1707

1708

1709

1710

1711

1712

1713

1714

1715

1716

1717

1718

1719

1720

1721

1722

1723

1724

1725

1726

1727

1728

Wong, C. E., Li, Y., Labbe, A., Guevara, D., Nuin, P., Whitty, B., ... Moffatt, B. A. (2006). Transcriptional profiling implicates novel interactions between abiotic stress and hormonal responses in Thellungiella, a close relative of Arabidopsis. Plant physiology, 140(4), 1437-1450. doi:10.1104/pp.105.070508

Wu, J., Zhou, W., Gong, X., \& Cheng, B. (2016). Expression of ZmHDZ4, a Maize Homeodomain-Leucine Zipper I Gene, Confers Tolerance to Drought Stress in Transgenic Rice. Plant Molecular Biology Reporter, 34(4), 845-853. doi:10.1007/s11105-015-0970-y

Wurzinger B., Mair A., Pfister B., Teige M. (2011). Cross-talk of calcium-dependent protein kinase and MAP kinase signaling. Plant Signal. Behav. 6:8-12. doi: 10.4161/psb.6.1.14012.

Xiong L., Schumaker K.S., Zhu J.K. (2002). Cell signaling during cold; drought; and salt stress. Plant Cell. 14:165-183. doi: 10.1105/tpc.010278.

Xu, Z., Ali, Z., Xu, L., He, X., Huang, Y., Yi, J., Zhang, D. (2016). The nuclear protein GmbZIP110 has transcription activation activity and plays important roles in the response to salinity stress in soybean. Scientific Reports, 6, 20366. http://doi.org/10.1038/srep20366

Yamaguchi-Shinozaki K, Shinozaki K. (2006). Transcriptional regulatory networks in cellular responses and tolerance to dehydration and cold stresses. Annu Rev Plant Biol 57:781803

Yamaguchi-Shinozaki K, Shinozaki K (1994) A novel cis-acting element in an Arabidopsis gene is involved in responsiveness to drought, low-temperature, or high-salt stress. Plant Cell $6: 251-264$

Yamanouchi U, Yano M, Lin HX, Ashikari M, Yamada K. (2002) Rice spotted leaf gene, Spl7, encodes a heat stress transcription factor protein. Proceedings of the National Academy of Sciences of the United States of America 99, 7530-7535. doi:10.1073/pnas.112209199

Yamasaki, K., Kigawa, T., Seki, M., Shinozaki, K., \& Yokoyama, S. (2013). DNA-binding domains of plant-specific transcription factors: structure, function, and evolution. Trends in Plant Science, 18(5), 267-276. doi:10.1016/j.tplants.2012.09.001

Yan J, Warburton M, Crouch J (2011) Association Mapping for Enhancing Maize (Zea mays L.) Genetic Improvement. Crop Sci 51: 433-449.

Yanhui C, Xiaoyuan Y, Kun H, Meihua L, Jigang L, Zhaofeng G, Zhiqiang L, Yunfei Z, Xiaoxiao W, Xiaoming Q, Yunping S, Li Z, Xiaohui D, Jingchu L, Xing-Wang D, Zhangliang C, Hongya G, Li-Jia Q (2006) The MYB transcription factor superfamily of Arabidopsis: expression analysis and phylogenetic comparison with the rice MYB family. Plant Mol Biol 60:107-124

Ying, S., \& Jing, D. Z. (2012). Cloning and characterization of a maize bZIP transcription factor, ZmbZIP72, confers drought and salt tolerance in transgenic Arabidopsis, 253-266. https://doi.org/10.1007/s00425-011-1496-7

Peer) reviewing PDF | (2019:02:35201:1:2:REVIEW 9 May 2019) 
1729

1730

1731

1732

1733

1734

1735

1736

1737

1738

1739

1740

1741

1742

1743

1744

1745

1746

1747

1748

1749

1750

1751

1752

1753

1754

1755

1756

1757

1758

1759

1760

1761

1762

1763

1764

1765

1766

1767

1768

Yu, X., Liu, Y., Wang, S., Tao, Y., Wang, Z., Shu, Y., Peng, H., Mijiti, A., Wang, Z., Zhang, H. (2016). CarNAC4, a NAC -type chickpea transcription factor conferring enhanced drought and salt stress tolerances in Arabidopsis. Plant Cell Rep. 35, 613-627

Yu, S., Liao, F., Wang, F., Wen, W., Li J., Mei, H., and Luo, L. (2012). Identification of rice transcription factors associated with drought tolerance using the Ecotilling method. PLoS One 7, e30765.

Zhang, X., Liu, X., Zhang, D., Tang, H., Sun, B., Li, C., ... Li, Y. (2017). Genome-wide identification of gene expression in contrasting maize inbred lines under field drought conditions reveals the significance of transcription factors in drought tolerance. PLOS ONE, 12(7), e0179477. doi:10.1371/journal.pone.0179477

Zhang, Y., Ge, F., Hou, F., Sun, W., Zheng, Q., Zhang, X., Shen, Y. (2017b). Transcription factors Responding to $\mathrm{Pb}$ stress in Maize. Genes, 8(9), 1-13. https://doi.org/10.3390/genes8090231

Zhang, X., Liu, X., Wu, L., Yu, G., Wang, X., \& Ma, H. (2015). The SsDREB Transcription Factor from the Succulent Halophyte Suaeda salsa Enhances Abiotic Stress Tolerance in Transgenic Tobacco. International Journal of Genomics, 2015, 875497. http://doi.org/10.1155/2015/875497

Zhang X, Wang L, Meng H, Wen H, Fan Y, Zhao J (2011) Maize ABP9 enhances tolerance to multiple stresses in transgenic Arabidopsis by modulating ABA signaling and cellular levels of reactive oxygen species. Plant Mol Biol 75:365-378

Zhao, X.,Peng, Y.,Zhang, J., Fang, P., \& Wu, B. (2018). Identification of QTLs and MetaQTLs for Seven Agronomic Traits in Multiple Maize Populations, 520 (april), 507-520. https://doi.org/10.2135/cropsci2016.12.0991

Zhao, Y., Ma, Q., Jin, X., Peng, X., Liu, J., Deng, L., Sheng, L. (2014). A Novel Maize Homeodomain - Leucine Zipper ( HD-Zip ) I Gene, Zmhdz10, Positively Regulates Drought and Salt Tolerance in Both Rice and Arabidopsis. Oxford Academic, 1, 1-33: https:// doi.org /10.1093/pcp/pcu054.

Zhao, Y., Zhou, Y., Jiang, H., Li, X., Gan, D., Peng, X., \& Zhu, S. (2011). Systematic Analysis of Sequences and Expression Patterns of Drought-Responsive Members of the HD-Zip Gene Family in Maize, 6(12), 20-21. https://doi.org/10.1371/journal.pone.0028488

Zhao JF, Sun ZF, Zheng J, Guo XY, Dong ZG, Huai JL, Gou M, He J, Jin Y, Wang J, Wang G. (2009). Cloning and characterization of a novel CBL-interacting protein kinase from maize. Plant Molecular Biology. 69: 661 1674 . https://doi.org/ 10.1007/s11103008-9445-y PMID: 19105030.

Zhou W, Jia C, Wu X, Hu R, Yu G, Zhang X, Liu J, Pan H. (2016). ZmDBF3, a Novel Transcription Factor from Maize (Zea mays L.), Is Involved in Multiple Abiotic Stress Tolerance, Plant Mol Biol Rep DOI 10.1007/s11105-015-0926-2

Zhu, Q., Zhang, J., Gao, X., Tong, J., Xiao, L., Li, W., Zhang, H. (2010). The Arabidopsis AP2/ERF transcription factor RAP2.6 participates in ABA, salt and osmotic stress responses.Gene.457:1-12. https://doi.org/10.1016/j.gene.2010.02.011

Peer) reviewing PDF | (2019:02:35201:1:2:REVIEW 9 May 2019) 
1769 Zhu J. K. (2002). Salt and drought stress signal transduction in plants. Annu. Rev. Plant Biol., 1770 53,247

1771 Zhuang, J., Deng, D.-X., Yao, Q.-H., Zhang, J., Xiong, F., Chen, J.-M., \& Xiong, A.-S. (2010). Discovery, phylogeny and expression patterns of AP2-like genes in maize. Plant Growth Regulation, 62(1), 51-58. doi:10.1007/s10725-010-9484-7

1774

1775

1776

1777

1778

1779

1780

1781 


\section{Figure 1}

A diagrammatic representation of gene expression and abiotic stress signal perception in plants via $A B A$-independent and ABA-dependent pathways.

Figure.1 A diagrammatic representation of gene expression and abiotic stress signal perception in plants via ABA-independent and ABA-dependent pathways (Modified from Gahlaut et al., 2016; Khan et al., 2018). Abbreviations: Abscisic acid (ABA), Reactive oxygen species (ROS), myeloblastosis oncogene (MYB), myelocytomatosis oncogene (MYC), Zincfinger homeodomain (ZF-HD) regulon, ABA-responsive element binding protein (AREB), ABAindependent regulons include; the NAC (CUC, NAM and ATAF), The cis-acting element (DRE), ABA-binding factor (ABF), The cis-acting element (CRE), Dehydration responsive element binding proteins (DREBs), C-repeat (CRT), (ZFR) zinc finger RNA binding protein, (NARC) NAC recognition site, (MYBRS) MYB recognition site, (MYCRS) MYC recognition site, Nuclear transcription factor Y (NF-Y), Heat Shock Factors (HSFs), Inducer of CBF Expression (ICE). 


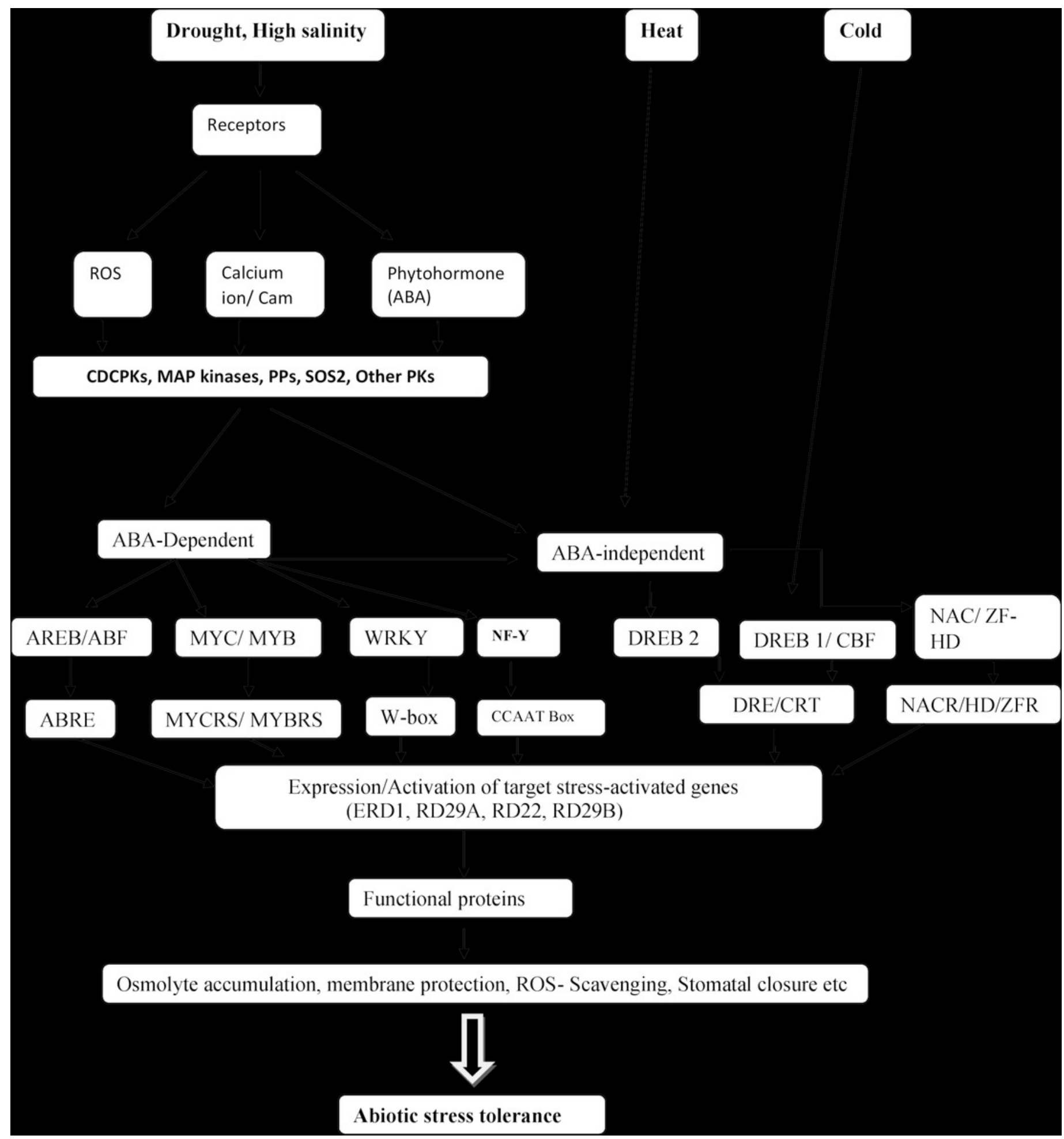




\section{Figure 2}

Cross-talk network between cis-acting elements and TFs in the ABA-independent and ABA-dependent pathways during abiotic stress

Cross-talk network between cis-acting elements and TFs in the ABA-independent and ABAdependent pathways during abiotic stress. Broken arrows indicate the protein-protein interactions. Thick green arrows show the major pathways which regulate many downstream genes (modified from Yamaguchi-Shinozaki and Shinozaki, 2006).

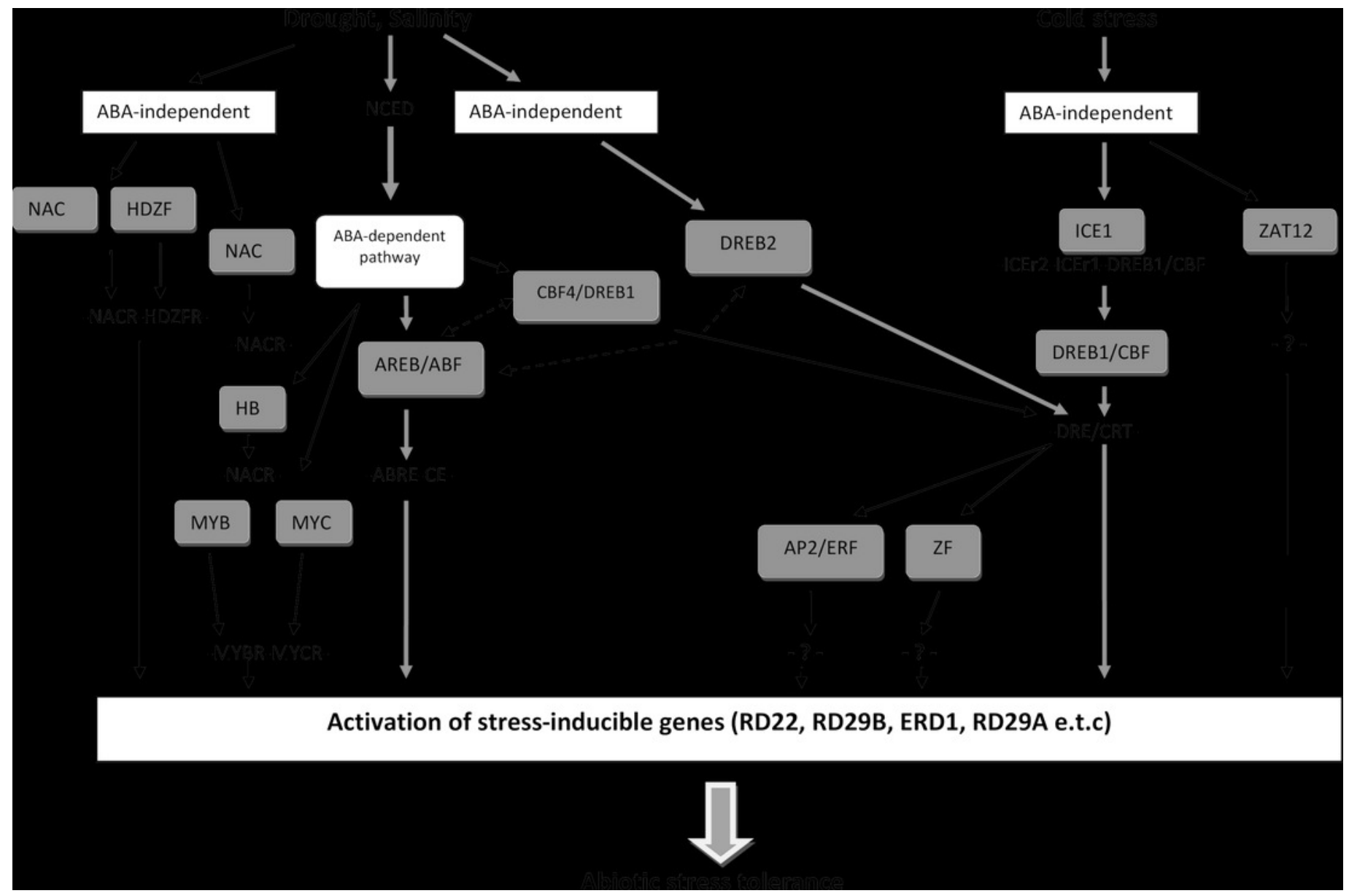




\section{Table $\mathbf{1}$ (on next page)}

Abiotic stress- related TF families, together with the specific TFs in Maize.

Abiotic stress- related TF families, together with the specific TFs, their characteristics, the regulons they control and their regulatory functions in the abiotic stress responses in Maize. 
1 Table 1 Abiotic stress- related TF families, together with the specific TFs, their characteristics,

2 the regulons they control and their regulatory functions in the abiotic stress responses in Maize.

3

\begin{tabular}{|c|c|c|c|c|c|}
\hline Family & $\begin{array}{l}\text { TFs in } \\
\text { Maize }\end{array}$ & $\begin{array}{l}\text { Cis-element } \\
\text { recognition }\end{array}$ & $\begin{array}{l}\text { Stress } \\
\text { response }\end{array}$ & $\begin{array}{l}\text { Downstream } \\
\text { genes }\end{array}$ & References \\
\hline \multirow[t]{6}{*}{$\mathrm{DREB} / \mathrm{CBF}$} & $Z m D R E B 2 A$ & $\begin{array}{l}\text { (DRE) } \\
\text { TACCGACAT }\end{array}$ & $\begin{array}{l}\text { Salt, Heat, } \\
\text { Drought, Cold }\end{array}$ & $\begin{array}{l}r d 29 A \\
r d 29 B, Z m G O L S 2\end{array}$ & Qin et al., 2007 \\
\hline & $Z m D B P 3$ & $\begin{array}{l}\text { (DRE) } \\
\text { TACCGACAT }\end{array}$ & Cold, salt & $\mathrm{U}$ & $\begin{array}{l}\text { Wang and Dong., } \\
2009\end{array}$ \\
\hline & $Z m D R E B 1 A$ & $\begin{array}{l}\text { (DRE/CRT) } \\
\text { G/ACCGAC }\end{array}$ & Drought, cold & $\begin{array}{l}\text { KIN1, } \\
\text { KIN2,COR15A } \\
\text { etc }\end{array}$ & Qin et al., 2004 \\
\hline & $Z m D B F 3$ & N/A & $\begin{array}{l}\text { Salt, drought, } \\
\text { freezing }\end{array}$ & $\mathrm{U}$ & Zhou et al., 2015 \\
\hline & $Z m D B P 4$ & $\begin{array}{l}\text { (DRE/CRT) } \\
\text { G/ACCGAC }\end{array}$ & Cold, drought & $\mathrm{U}$ & Wang et al., 2011 \\
\hline & ZmDREB2.7 & $\begin{array}{l}\text { (DRE) } \\
\text { A/GCCGAC }\end{array}$ & Drought & $\mathrm{U}$ & Liu et al., 2013 \\
\hline \multirow[t]{6}{*}{ MYB/MYC } & ZmMYB30 & $\begin{array}{l}\text { (MYBR) } \\
\text { TAACNA/G }\end{array}$ & $\begin{array}{l}\text { Salt, drought, } \\
\text { ABA }\end{array}$ & $\begin{array}{l}R D 20, R D 29 A, \\
R b o h D \text { e.t.c }\end{array}$ & Chen et al., 2015 \\
\hline & ZmMYB36 & N/A & $\begin{array}{l}\text { Salt, drought, } \\
\text { ABA }\end{array}$ & $\mathrm{U}$ & Chen et al., 2015 \\
\hline & ZmMYB95 & N/A & $\begin{array}{l}\text { Salt, drought, } \\
\text { ABA }\end{array}$ & $\mathrm{U}$ & Chen et al., 2015 \\
\hline & ZmMYB53 & $\mathrm{N} / \mathrm{A}$ & Cold & $\mathrm{U}$ & Chen et al., 2015 \\
\hline & ZmMYB31 & N/A & $\begin{array}{l}\text { Sensitivity to } \\
\text { UV radiation }\end{array}$ & $\begin{array}{l}\mathrm{ZmF5H}, \\
\mathrm{ZmCOMT,C3H,} \\
\text { and } \mathrm{ZmActin}\end{array}$ & $\begin{array}{l}\text { Fornale et al., } \\
2010\end{array}$ \\
\hline & $Z m M Y B-R 1$ & N/A & $\begin{array}{l}\text { Cold, high } \\
\text { salinity, } \\
\text { drought, ABA } \\
\text { and heat }\end{array}$ & $\mathrm{U}$ & Liu et al., 2012 \\
\hline \multirow[t]{6}{*}{ bZIP } & \multirow[t]{2}{*}{ ZmbZIP60 } & \multirow[t]{2}{*}{$\begin{array}{l}\text { (ABRE) } \\
\text { ACGTGGC }\end{array}$} & $\begin{array}{l}\text { Dehydration, } \\
\text { high salinity, } \\
\text { ABA }\end{array}$ & $\mathrm{U}$ & Wang et al., 2012 \\
\hline & & & Heat stress & $\mathrm{U}$ & Li et al., 2018 \\
\hline & ZmbZIP17 & N/A & $\begin{array}{l}\text { Drought, ABA, } \\
\text { heat, Salt }\end{array}$ & $\mathrm{U}$ & Jia et al., 2009 \\
\hline & $\begin{array}{l}Z m b Z I P 54 \\
\text { and } \\
Z m b Z I P 107\end{array}$ & $\begin{array}{l}\text { (ABRE) } \\
\text { ACGTGGC }\end{array}$ & Lead $(\mathrm{Pb})$ & $\mathrm{U}$ & $\begin{array}{l}\text { Zhang et al., } \\
2017\end{array}$ \\
\hline & mlip15 & $\begin{array}{l}\text { (ABRE) } \\
\text { ACGTGGC }\end{array}$ & $\begin{array}{l}\text { Low } \\
\text { temperature, } \\
\text { salt, ABA } \\
\end{array}$ & $\mathrm{U}$ & $\begin{array}{l}\text { Kusano et al., } \\
1995\end{array}$ \\
\hline & $Z m b Z I P 72$ & (ABRE) & ABA, drought, & $R a b 18, r d 29 B$ & Ying and Jing ., \\
\hline
\end{tabular}




\begin{tabular}{|c|c|c|c|c|c|}
\hline & & ACGTGGC & high salinity, & HISI-3 e.t.c & 2012 \\
\hline & $A B P 9$ & $\begin{array}{l}\text { (ABRE) }(\mathrm{C} / \mathrm{T}) \\
\text { ACGTGGC }\end{array}$ & $\begin{array}{l}\text { ABA, drought, } \\
\mathrm{H}_{2} \mathrm{O}_{2} \text {, salt }\end{array}$ & $\begin{array}{l}K I N 1, C O R 15 A \text {, } \\
P P 2 C, A Z F 2 \\
\text { e.t.c }\end{array}$ & $\begin{array}{l}\text { Zhang et al., } \\
2011\end{array}$ \\
\hline & ZmbZIP4 & $\begin{array}{l}\text { (ABRE) }(\mathrm{C} / \mathrm{T}) \\
\text { ACGTGGC }\end{array}$ & $\begin{array}{l}\text { Heat, cold, } \\
\text { salinity and } \\
\text { ABA }\end{array}$ & $\begin{array}{l}\text { ZmLEA2, } \\
\text { ZmRD20, } \\
\text { ZMRab18, } \\
\text { ZmGEA6 e.t.c }\end{array}$ & Ma et al., 2018 \\
\hline \multirow[t]{7}{*}{ NAC } & ZmSNACl & $\mathrm{N} / \mathrm{A}$ & $\begin{array}{l}\text { Low } \\
\text { temperature, } \\
\text { ABA, high } \\
\text { salinity, } \\
\text { drought }\end{array}$ & U & Lu et al., 2012 \\
\hline & ZmNAC55 & N/A & $\begin{array}{l}\text { High salinity, } \\
\text { cold, drought, } \\
\text { ABA }\end{array}$ & $\begin{array}{l}\text { RD29B, LEA14, } \\
R D 17, Z A T 10 \\
\text { e.t.c }\end{array}$ & Mao et al., 2016 \\
\hline & Zma006493 & N/A & Drought & $\mathrm{U}$ & Min et al., 2015 \\
\hline & Zma000584 & N/A & Drought, cold & $\mathrm{U}$ & Min et al., 2015 \\
\hline & Zma001259 & N/A & $\begin{array}{l}\text { Drought, salt, } \\
\text { cold }\end{array}$ & $\mathrm{U}$ & Min et al., 2015 \\
\hline & ZmSNAC052 & N/A & Drought, cold & $\mathrm{U}$ & Min et al., 2015 \\
\hline & Zma029150 & N/A & Drought, salt & $\mathrm{U}$ & Min et al., 2015 \\
\hline \multirow[t]{6}{*}{ WRKY } & ZmWRKY17 & $\begin{array}{l}\text { (W-box) } \\
\text { TTGACC/T }\end{array}$ & $\begin{array}{l}\text { Drought, salt, } \\
\text { ABA }\end{array}$ & $\begin{array}{l}\text { bHLH92, KINI, } \\
\text { DREBIF e.t.c }\end{array}$ & Cai et al., 2017 \\
\hline & ZmWRKY33 & $\begin{array}{l}\text { (W-box) } \\
\text { TTGACC/T }\end{array}$ & $\begin{array}{l}\text { High salinity, } \\
\text { dehydration, } \\
\text { cold, ABA }\end{array}$ & $\begin{array}{l}R D 29 A \text { and } \\
D R E B 1 B\end{array}$ & Li et al., 2013 \\
\hline & ZmWRKY44 & $\begin{array}{l}\text { (W-box) } \\
\text { TTGACC/T }\end{array}$ & $\begin{array}{l}\text { Salt, high } \\
\text { temperature, } \\
\mathrm{ABA}, \mathrm{H}_{2} \mathrm{O}_{2}\end{array}$ & $\mathrm{U}$ & Wang., 2014 \\
\hline & ZmWRKY58 & $\begin{array}{l}\text { (W-box) } \\
\text { TTGACC/T }\end{array}$ & $\begin{array}{l}\text { Drought, ABA, } \\
\text { Salt }\end{array}$ & $\mathrm{U}$ & Cai et al.,2014 \\
\hline & ZmWRKY106 & $\begin{array}{l}\text { (W-box) } \\
\text { TTGACC/T }\end{array}$ & $\begin{array}{l}\text { Drought, high } \\
\text { temperature, } \\
\text { ABA, Salt }\end{array}$ & $\begin{array}{l}\text { CuZnSOD, } \\
D R E B 2 A \text {, } \\
\text { NCED6 and } \\
R D 29 A\end{array}$ & $\begin{array}{l}\text { Wang et al., } \\
2018 \mathrm{c}\end{array}$ \\
\hline & ZmWRKY40 & $\begin{array}{l}\text { (W-box) } \\
\text { TTGACC/T }\end{array}$ & $\begin{array}{l}\text { Drought, High } \\
\text { salinity, High } \\
\text { temperature, } \\
\text { ABA }\end{array}$ & $\begin{array}{l}D R E B 2 B, S T Z \\
\text { and } R D 29 A\end{array}$ & $\begin{array}{l}\text { Wang et al., } \\
2018 \mathrm{a}\end{array}$ \\
\hline \multicolumn{6}{|l|}{ Others } \\
\hline \multirow[t]{2}{*}{ HD-Zip } & Zmhdz10 & CAATAATTG & Salt, ABA & $\begin{array}{l}\text { ABI1, RD22, } \\
\text { P5CSI e.t.c }\end{array}$ & Zhao et al., 2018 \\
\hline & ZmHDZ4 & CAATAATTG & Drought & $\mathrm{U}$ & Wu et al., 2016 \\
\hline HSP & ZmERD2 & $\mathrm{N} / \mathrm{A}$ & $\begin{array}{l}\text { Heat, salinity, } \\
\text { cold, PEG, }\end{array}$ & $\mathrm{U}$ & Jinhui et al., 2015 \\
\hline
\end{tabular}




\begin{tabular}{|l|l|l|l|l|l|}
\hline NF-Y & ZmNF-YB16 & CCAAT & $\begin{array}{l}\text { Dehydration } \\
\text { Drought }\end{array}$ & $\begin{array}{l}\text { P5CS, Atj3, } \\
\text { AtDFC82, } \\
\text { HSP70 e.t.c }\end{array}$ & $\begin{array}{l}\text { Wang et al., } \\
2018 \mathrm{~b}\end{array}$ \\
\hline & $Z m N F-Y B 2$ & CCAAT & Drought & U & $\begin{array}{l}\text { Nelson et al., } \\
2007\end{array}$ \\
\hline & $Z m N F-Y A 3$ & CCAAT & $\begin{array}{l}\text { Drought, high } \\
\text { temperature }\end{array}$ & $\begin{array}{l}\text { ZmbHLH92, } \\
\text { ZmMYC4 and } \\
\text { ZmFAMA }\end{array}$ & Su et al., 2018 \\
\hline
\end{tabular}

4 N/A- The cis-acting element is unknown, $\mathrm{U}$ - unknown

5 


\section{Table 2 (on next page)}

Abiotic stress responses of over-expressing Maize TFs in transgenic plants.

Represents the abiotic stress responses of over-expressing Maize TFs in transgenic plants. 
2 Table 2 Represents the abiotic stress responses of over-expressing Maize TFs in transgenic 3 plants.

4

\begin{tabular}{|c|c|c|c|c|}
\hline Family & Gene & $\begin{array}{l}\text { Stress } \\
\text { Tolerance }\end{array}$ & $\begin{array}{l}\text { Transgenic } \\
\text { Plant }\end{array}$ & References \\
\hline \multirow[t]{2}{*}{ MYB/MYC } & ZmMYB30 & Salt & Arabidopsis & $\begin{array}{l}\text { Chen et al., } \\
2015\end{array}$ \\
\hline & $Z m M Y B 31$ & $\begin{array}{l}\text { Sensitivity to UV } \\
\text { irradiation }\end{array}$ & Arabidopsis & $\begin{array}{l}\text { Fornale et al., } \\
2010\end{array}$ \\
\hline \multirow[t]{6}{*}{ DREB/CBF } & $Z m D R E B 2 A$ & Drought, heat & Arabidopsis & Qin et al., 2007 \\
\hline & $Z m D B P 3$ & Cold, salt & Arabidopsis & $\begin{array}{l}\text { Wang and } \\
\text { Dong., } 2009\end{array}$ \\
\hline & $Z m D B F 3$ & Salt, freezing & $\begin{array}{l}\text { yeast } \\
\text { (Saccharomyces } \\
\text { cerevisiae) }\end{array}$ & $\begin{array}{l}\text { Zhou et al., } \\
2015\end{array}$ \\
\hline & ZmDREB $1 A$ & $\begin{array}{l}\text { Drought, } \\
\text { Freezing }\end{array}$ & Arabidopsis & Qin et al., 2004 \\
\hline & ZmDREB2.7 & Drought & Arabidopsis & Liu et al., 2013 \\
\hline & $Z m D B P 4$ & Drought, cold & Arabidopsis & $\begin{array}{l}\text { Wang et al., } \\
2011\end{array}$ \\
\hline \multirow[t]{4}{*}{ bZIP } & ZmbZIP60 & $\begin{array}{l}\text { Dithiothreitol } \\
\text { (DDT) }\end{array}$ & Arabidopsis & $\begin{array}{l}\text { Wang et al., } \\
2012\end{array}$ \\
\hline & $Z m b Z I P 72$ & $\begin{array}{l}\text { Drought, partial } \\
\text { salinity }\end{array}$ & Arabidopsis & $\begin{array}{l}\text { Ying and Jing ., } \\
2012\end{array}$ \\
\hline & \multirow[t]{2}{*}{$A b p 9$} & $\begin{array}{l}\text { Salt, osmotic } \\
\text { stress }\end{array}$ & $\begin{array}{l}\text { Cotton } \\
\text { (Gossypium } \\
\text { hirsutum) }\end{array}$ & $\begin{array}{l}\text { Wang et al., } \\
2017\end{array}$ \\
\hline & & $\begin{array}{l}\text { Drought, ABA, } \\
\text { Salt }\end{array}$ & Arabidopsis & $\begin{array}{l}\text { Zhang et al., } \\
2011\end{array}$ \\
\hline \multirow[t]{5}{*}{ NAC } & \multirow[t]{2}{*}{ ZmSNAC1 } & $\begin{array}{l}\text { Sensitivity to } \\
\text { ABA, osmotic } \\
\text { stress }\end{array}$ & \multirow[t]{2}{*}{ Arabidopsis } & \multirow[t]{2}{*}{ Lu et al., 2012} \\
\hline & & $\begin{array}{l}\text { Tolerance to } \\
\text { dehydration }\end{array}$ & & \\
\hline & \multirow[t]{2}{*}{$Z m N A C 55$} & $\begin{array}{l}\text { Sensitivity to } \\
\text { ABA }\end{array}$ & \multirow[t]{2}{*}{ Arabidopsis } & \multirow[t]{2}{*}{ Mao et al., 2016} \\
\hline & & $\begin{array}{l}\text { Tolerance to } \\
\text { drought }\end{array}$ & & \\
\hline & $Z m N A C 111$ & Drought & $\begin{array}{l}\text { Maize (Zea } \\
\text { mays) }\end{array}$ & Mao et al., 2015 \\
\hline WRKY & $Z m W R K Y 17$ & Sensitivity to salt & Arabidopsis & Cai et al., 2017 \\
\hline
\end{tabular}




\begin{tabular}{|c|c|c|c|c|}
\hline & & $\begin{array}{l}\text { Tolerance to } \\
\text { ABA }\end{array}$ & & \\
\hline & ZmWRKY33 & Salt & Arabidopsis & Li et al., 2013 \\
\hline & $Z m W R K Y 44$ & Sensitivity to salt & Arabidopsis & Wang., 2014 \\
\hline & $Z m W R K Y 58$ & $\begin{array}{l}\text { Enhanced } \\
\text { tolerance to } \\
\text { drought, salt }\end{array}$ & $\begin{array}{l}\text { Rice (Oryza } \\
\text { sativa) }\end{array}$ & Cai et al., 2014 \\
\hline & ZmWRKY106 & $\begin{array}{l}\text { Drought, heat } \\
\text { stress }\end{array}$ & Arabidopsis & $\begin{array}{l}\text { Wang et al., } \\
2018 \mathrm{c}\end{array}$ \\
\hline & $Z m W R K Y 40$ & drought & Arabidopsis & $\begin{array}{l}\text { Wang et al., } \\
2018 \mathrm{a}\end{array}$ \\
\hline \multicolumn{5}{|l|}{ Others } \\
\hline HSF & $\mathrm{ZmHsf06}$ & $\begin{array}{l}\text { Drought, } \\
\text { thermotolerance }\end{array}$ & Arabidopsis & Li et al., 2015 \\
\hline \multirow[t]{4}{*}{ HD-Zip } & Zmhdz10 & $\begin{array}{l}\text { Drought, salt } \\
\text { Sensitivity to } \\
\text { ABA }\end{array}$ & $\begin{array}{l}\text { Rice (Oryza } \\
\text { sativa) }\end{array}$ & \multirow[t]{2}{*}{$\begin{array}{l}\text { Zhao et al., } \\
2018\end{array}$} \\
\hline & & Drought, salt & Arabidopsis & \\
\hline & ZmHDZ4 & Drought & $\begin{array}{l}\text { Rice (Oryza } \\
\text { sativa) }\end{array}$ & Wu et al., 2016 \\
\hline & Zmhdz12 & Drought & Arabidopsis & $\begin{array}{l}\text { Qing and Wei., } \\
2018\end{array}$ \\
\hline \multirow[t]{2}{*}{ NF-Y } & $Z m N F-Y B 2$ & Drought & $\begin{array}{l}\text { Maize (Zea } \\
\text { mays) }\end{array}$ & $\begin{array}{l}\text { Nelson et al., } \\
2007\end{array}$ \\
\hline & $Z m N F-Y B 16$ & $\begin{array}{l}\text { Drought, } \\
\text { Dehydration }\end{array}$ & $\begin{array}{l}\text { Maize (Zea } \\
\text { mays) }\end{array}$ & $\begin{array}{l}\text { Wang et al., } \\
2018 b\end{array}$ \\
\hline
\end{tabular}

5 